\title{
Thermal equation of state and stability of $\left(\mathrm{Mg}_{0.06} \mathrm{Fe}_{0.94}\right) \mathrm{O}$
}

\author{
June K. Wicks ${ }^{\mathrm{a}, \mathrm{c}}$, Jennifer M. Jackson ${ }^{\mathrm{a}}$, Wolfgang Sturhahn ${ }^{\mathrm{a}}$, Kirill K. \\ Zhuravlev $^{\mathrm{b}}$, Sergey N. Tkachev ${ }^{\mathrm{b}}$, Vitali B. Prakapenka ${ }^{\mathrm{b}}$ \\ ${ }^{a}$ Division of Geological and Planetary Sciences, California Institute of Technology, \\ Pasadena, California, USA \\ ${ }^{b}$ Center for Advanced Radiation Sources, University of Chicago, Chicago, IL 60637, USA \\ ${ }^{c}$ Now at Department of Geosciences, Princeton University, Princeton, NJ, USA
}

\begin{abstract}
We present the pressure-volume-temperature $(P-V-T)$ equation of state of polycrystalline $\left(\mathrm{Mg}_{0.06} \mathrm{Fe}_{0.94}\right) \mathrm{O}(\mathrm{Mw} 94)$ determined from laser-heated x-ray diffraction experiments up to $122 \mathrm{GPa}$ and $2100 \mathrm{~K}$, conditions approaching those of the deep mantle. We conducted two sets of experiments, one with an in situ Fe metal oxygen fugacity buffer and one without such a buffer. The internal pressure markers used in these experiments were $B 2-\mathrm{NaCl}$ and $h c p$ - $\mathrm{Fe}$ in the buffered experiment and $B 2-\mathrm{NaCl}$ in the unbuffered experiment. In the sampled $P-T$ range of the high temperature part of this study, only the $B 1$ structure of Mw94 was observed, indicating that the addition of $\mathrm{Mg}$ to $\mathrm{FeO}$ stabilizes the $B 1$ phase with respect to the $B 8$ phase at these conditions. Both datasets were fit to a Birch-Murnaghan and Mie-Grüneisen-Debye thermal equation of state using a new open-source fitting routine, also presented here. Analysis of these data sets using the same internal pressure marker shows that the $P-V-T$ data of Mw94 obtained in the unbuffered experiment are well explained by the equation of state parameters determined from the buffered data set. We have also compared the thermal equation of state of Mw94 with that of wüstite and conclude that Mw94 has measurably distinct thermoelastic properties compared with those of wüstite. We use the results obtained in the buffered experiment to
\end{abstract}

Email address: jwicks@princeton.edu (June K. Wicks)

Preprint submitted to Physics of the Earth and Planetary Interiors 
determine the density and bulk sound velocity of Mw94 at the base of the mantle and compare these values to geophysical observations of ultralow-velocity zones.

Keywords: equations of state, core-mantle boundary, $(\mathrm{Mg}, \mathrm{Fe}) \mathrm{O}$

\section{Introduction}

\subsection{Motivation}

Iron-poor members of the periclase-wüstite $(\mathrm{MgO}-\mathrm{FeO})$ solid solution may 4 comprise up to $20 \%$ of the Earth's lower mantle. According to the "pyrolite" 5 model, the chemistry of this phase contains 10-20\% FeO (Ringwood, 1975). 6 The simplest assumption is that the lower mantle is homogeneous, yet seismic studies reveal discontinuities and lateral heterogeneity in the deep mantle that suggest lateral chemical inhomogeneities (Garnero et al., 2007). Chemical analyses of magma associated with hotspot volcanism from mantle plumes reportedly sourced from the lower mantle also give evidence for chemical heterogeneity, promising a more complex lower mantle (Mukhopadhyay, 2012). To understand the role of $(\mathrm{Mg}, \mathrm{Fe}) \mathrm{O}$ in these variations, the thermodynamic and elasticity systematics of ferropericlase, $\left(\mathrm{Mg}_{1-x} \mathrm{Fe}_{x}\right) \mathrm{O}$ with $x<0.5$, has been extensively studied as a function of composition, pressure, and temperature. However, more iron-rich compositions of $(\mathrm{Mg}, \mathrm{Fe}) \mathrm{O}$ have not been explored in the same detail.

Ultralow-velocity zones (ULVZs) at the core-mantle boundary give insight into the chemical heterogeneity of the lowermost mantle. As their name implies, ULVZs are characterized by very low seismic wave velocities (10-30\%) (e.g. Garnero and Helmberger, 1998; Helmberger et al., 2000; Rost et al., 2006; Sun et al., 2013). Requiring concomitant density increase and sound velocity decrease with respect to the surrounding mantle, ULVZs are best explained by Fe-enrichment. Recent considerations of a crystallizing primordial magma ocean show that enrichment of $\mathrm{Fe}$ in the lowermost mantle is possible, preserved as 
either iron-rich solids or residual melt (Labrosse et al., 2007; Lee et al., 2010; Nomura et al., 2011).

Incorporation of $40 \% \mathrm{Fe}$ into magnesium silicate post-perovskite has been found to reduce shear wave velocities to $33 \%$ lower than that of the 1D Preliminary Reference Earth Model (PREM) (Mao et al., 2006; Dziewonski and Anderson, 1981). An iron-rich oxide, namely $\left(\mathrm{Mg}_{0.16} \mathrm{Fe}_{0.84}\right) \mathrm{O}$, also has low shear wave velocities - 50\% lower than that of PREM (Wicks et al., 2010). Partial melting has also been suggested as a plausible mechanism (Williams et al., 1998; Lay et al., 2004; Labrosse et al., 2007).

Dynamic models have been used to explore the stability and topology of ULVZs to differentiate the observable characteristics of various candidate assemblages. Hernlund and Tackley (2007) found that the amount of partial melt required to decrease the sound velocities of a phase assemblage to match ULVZs would percolate and pool at the base of the mantle, a result that could be prevented if the ULVZ were stirred (Hernlund and Jellinek, 2010). Dynamic models exploring solid ULVZs show that ULVZ shape can be correlated to chemical density anomaly, which in turn can be used to explore the tradeoff between density and sound velocities of (Mg,Fe)O and bridgmanite (Bower et al., 2011; Sun et al., 2013).

We are motivated, therefore, to measure the pressure-volume-temperature equation of state of iron-rich $(\mathrm{Mg}, \mathrm{Fe}) \mathrm{O}$, so that the density of iron-rich ULVZs can be properly modeled, and the relationship between sound velocity and density can further constrain the composition of ULVZs.

\subsection{Previous experimental studies}

Previous pressure-volume-temperature $(P-V-T)$ studies have shown that the $\mathrm{MgO}-\mathrm{FeO}$ solid solution is complicated by the existence of phase transitions, a spin transition, and defect clustering as a function of $\mathrm{FeO}$ component (e.g. Lin et al., 2003; Fei et al., 2007a; Lin et al., 2005; Speziale et al., 2005; Kantor et al., 2009; Mao et al., 2011). The MgO endmember is known to be cubic beyond the pressure and temperature conditions of the Earth's mantle (Duffy 
and Ahrens, 1993). The FeO endmember is thought to be cubic at the pressures and temperatures of the interior of the Earth, but at lower temperatures is found to transform to a rhombohedral structure at moderate pressures (e.g. Shu et al., 1998) and to the $B 8$ NiAs structure at higher pressures (e.g. Fei and Mao, 1994; Fischer et al., 2011b).

At $300 \mathrm{~K}$, iron-rich $(\mathrm{Mg}, \mathrm{Fe}) \mathrm{O}$ undergoes a cubic to rhombohedral phase transition at 8-40 GPa, with a phase transition pressure sensitive to both composition and hydrostaticity. Studies of the bulk modulus at 0 GPa as a function of composition show differing trends due to sample stoichiometry. Studies of non-stoichiometric, iron-rich $(\mathrm{Mg}, \mathrm{Fe}) \mathrm{O}$ show that both $K_{S}$ and $K_{T}$ decreases as a function of Fe concentration (Jacobsen et al., 2002; Richet et al., 1989), where $K_{S}$ is determined from measurements of volume, composition, and of $V_{P}$ and $V_{S}$ using ultrasonic interferometry, and $K_{T}$ is determined in a $P-V$ compression study. The trend is opposite for stoichiometric samples, where ultrasonic interferometry studies for iron-poor samples display a positive trend of $K_{S}$ with increasing iron content (Jacobsen et al., 2002). In the iron endmember, $K_{T}$ does indeed depend on stoichiometry, with $\mathrm{Fe}_{0.99} \mathrm{O}$ being much less compressible than $\mathrm{Fe}_{<0.98} \mathrm{O}$ (Zhang, 2000).

Thermal expansion, $\alpha=\frac{1}{V}\left(\frac{\partial V}{\partial T}\right)_{P}$ has been shown to be insensitive to $\mathrm{Fe}$ content for Mg-containing ferropericlase (Zhang and Kostak, 2002; Westrenen et al., 2005; Komabayashi et al., 2010; Mao et al., 2011). Yet, it appears to be sensitive to defect concentration. In the Fe end member, $\alpha$ is about $30 \%$ larger for $\mathrm{Fe}_{0.942} \mathrm{O}$ than $\mathrm{Fe}_{0.987} \mathrm{O}$ at pressures and temperatures up to $5.4 \mathrm{GPa}$ and $1073 \mathrm{~K}$ (Zhang and Zhao, 2005). In this study, we aim to determine the $P-V-T$ equation of state $\left(\mathrm{Mg}_{0.06} \mathrm{Fe}_{0.94}\right) \mathrm{O}$ at conditions approaching those of the deep mantle to constrain the thermoelasticity of iron-rich $(\mathrm{Mg}, \mathrm{Fe}) \mathrm{O}$ and to see if these aforementioned trends apply to iron-rich $(\mathrm{Mg}, \mathrm{Fe}) \mathrm{O}$.

\subsection{Experimental considerations}

In this paper we discuss two types of experiments, "buffered" and "unbuffered". In previous high- $P T$ experiments on wüstite, an in situ Fe metal 
oxygen buffer has been used (Fischer et al., 2011b; Seagle et al., 2008; Ozawa et al., 2010). The motivation of using such a buffer has been to decrease the vacancy population of wüstite at high pressures and temperatures, as some studies indicate that the thermoelastic properties of wüstite vary as a function of vacancy concentration (Zhang, 2000; Zhang and Zhao, 2005).

\section{Materials and Methods}

Polycrystalline $\left(\mathrm{Mg}_{0.06}{ }^{57} \mathrm{Fe}_{0.94}\right) \mathrm{O}$ was synthesized from ${ }^{57} \mathrm{Fe}(95 \%$ enriched, Isoplex) and $\mathrm{MgO}$ powders in a 1 atm gas-mixing furnace at $1673 \mathrm{~K}$ for two runs of 20 hours each. $\mathrm{A} \mathrm{H}_{2} / \mathrm{CO}_{2}$ gas mixture was used to control the oxygen fugacity of the synthesis to just above that of the iron-wüstite fugacity buffer $\left(\log f_{\mathrm{O}_{2}}=-9\right)$. Sample composition was measured using a JEOL-JXA-8200 electron microprobe, reporting a composition of $\left(\mathrm{Mg}_{.058(1)} \mathrm{Fe}_{.942(1)}\right) \mathrm{O}$, where the number in parentheses is the error on the last digit. A conventional Mössbauer spectrum (Figure 1, inset) caps the ferric content at $5 \%$ of the total iron, thus capping the vacancy concentration at $5 \%$.

Two experiments were conducted in this study. For the unbuffered experiment, a symmetric diamond anvil cell with $300 \mu \mathrm{m}$-culet diamonds was prepared. $\left(\mathrm{Mg}_{0.06} \mathrm{Fe}_{0.94}\right) \mathrm{O}$, hereafter referred to as Mw94, was lightly ground with $\mathrm{NaCl}$ powder (1:1 by volume) in an agate mortar under ethanol, allowed to dry, then pressed into a pellet. This mixture was loaded between two thin $\mathrm{NaCl}$ plates $(<10 \mu \mathrm{m})$, and the remaining space in the rhenium gasket sample chamber was filled with neon using the COMPRES/GSECARS gas-loading system (Rivers et al., 2008). To keep the $\mathrm{NaCl}$ dehydrated, the pellet was consistently stored in a desiccator when not in use, and the loaded diamond anvil was placed under vacuum for about one hour and purged with argon before being put into the gas-loading system.

We conducted a second experiment with an in situ Fe metal oxygen buffer for comparison. In this second, buffered, high pressure experiment, $250 \mu \mathrm{m}$-culet diamonds were used. Otherwise, the preparation differed in that the sample 
pellet (Mw94 and $\mathrm{NaCl})$ also included a Fe metal (1:1 Mw94:Fe by weight) as an in situ oxygen buffer and pressure marker. Thus, both experiments contained an intimate mixture of $\mathrm{Mw} 94$ and $\mathrm{NaCl}$ in the sample pellet, so that $\mathrm{NaCl}$ may be used as a common pressure marker to compare the results of the buffered and unbuffered experiments.

The high temperature powder X-ray diffraction (XRD) experiments were conducted at the 13-ID-D beamline (GeoSoilEnviroCars) at the Advanced Photon Source, Argonne National Laboratory. Using an incident X-ray beam of $\lambda=$ $0.3344 \AA$ and focus spot size of $4 \mu \mathrm{m} \times 4 \mu \mathrm{m}$, angle-dispersive X-ray diffraction patterns were recorded onto a MAR165 CCD detector and subsequently integrated using Fit2D (Hammersley et al., 1996). $\mathrm{CeO}_{2}$ was used to calibrate the sample to detector distance at 1 bar. Samples were compressed to about 35 GPa at room temperature before heating. High temperatures were achieved in situ by laser heating from both sides by $1.064 \mu \mathrm{m}$ Yb fiber lasers with 'flat top' profiles (Prakapenka et al., 2008) and temperatures determined spectroradiometrically (e.g. Heinz and Jeanloz, 1987; Shen et al., 2001) using the gray body approximation over the $600-800 \mathrm{~nm}$ range of thermal emission. Temperatures were measured during the collection of the diffraction patterns. In the buffered experiment, only the upstream temperatures were used due to technical difficulties with the downstream temperature determinations. The diffraction peaks were relatively sharp compared to ambient temperature spectra, indicating that temperature gradients are likely small. Example XRD patterns are shown in Figure 1.

The $2 \theta$ angles corresponding to lattice reflections of $\left(\mathrm{Mg}_{0.06} \mathrm{Fe}_{0.94}\right) \mathrm{O}, \mathrm{NaCl}$, $\mathrm{Fe}$, and Ne were determined by fitting the patterns with Voigt peaks using Igor Pro (WaveMetrics, Lake Oswego, OR, USA). In the multi-peak fitting routine in Igor Pro, XRD pattern backgrounds were fit locally with a cubic function. Unit cell volumes were determined using unweighted linear regression using the Unit Cell refinement software package (Holland and Redfern, 1997), which assumes a minimum uncertainty of 0.005 degrees on each lattice reflection, with errors on the unit cell weighted by goodness of fit. 


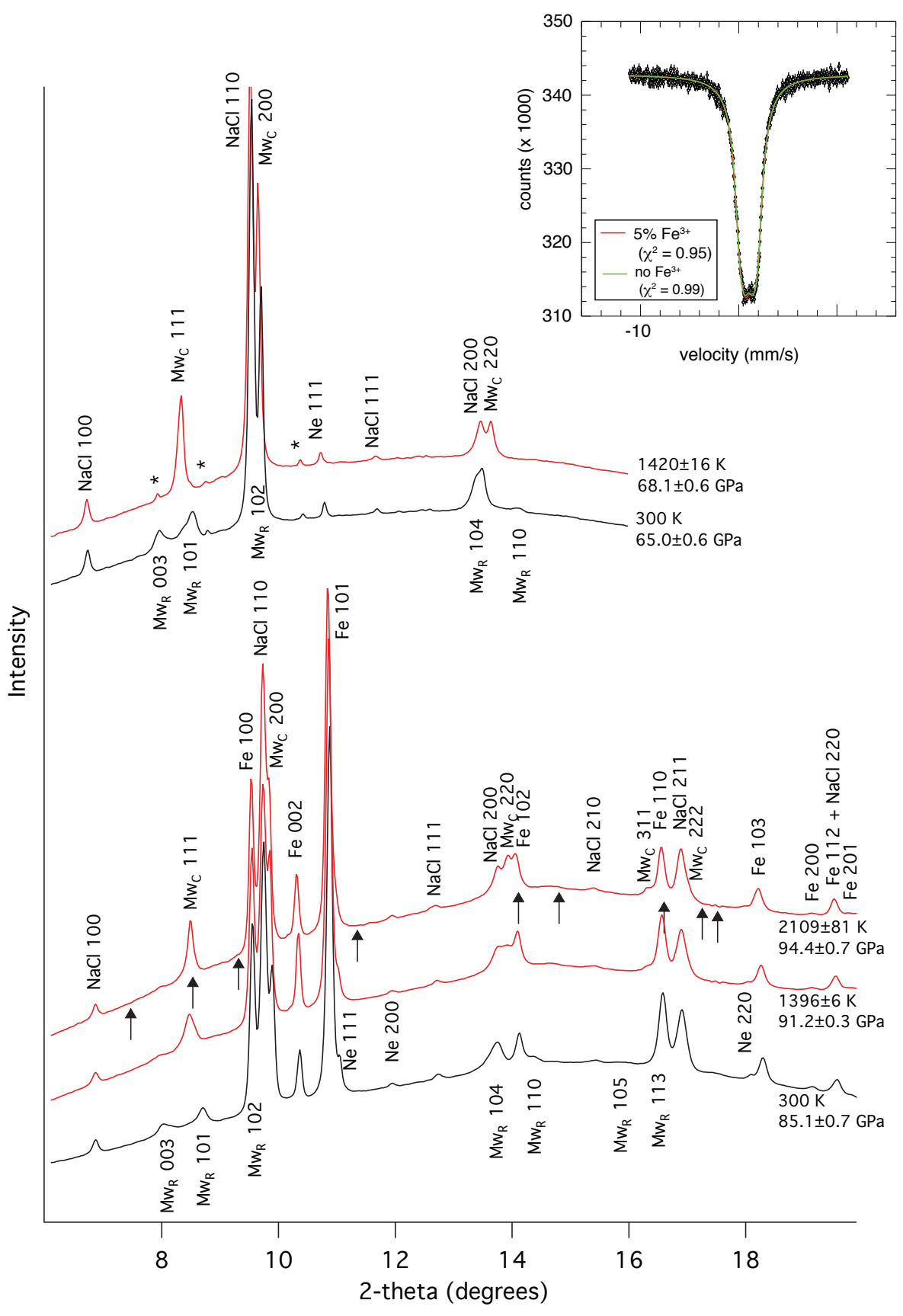

Figure 1: Example integrated XRD patterns showing peak identifications for $B 2-\mathrm{NaCl}, h c p$ - $\mathrm{Fe}$, and Ne. Pressures were determined using the equation of state of $B 2-\mathrm{NaCl}$ (Fei et al., 2007b) for the unbuffered dataset (top two patterns), and hcp-Fe (Dewaele et al., 2006; Murphy et al., 2011) for the buffered dataset (bottom three patterns). $\left(\mathrm{Mg}_{0.06} \mathrm{Fe}_{0.94}\right) \mathrm{O}$ is rhombohedral at room temperature $\left(\mathrm{Mw}_{R}, R-3 m\right)$ and cubic at high temperature $\left(\mathrm{Mw}_{C}, F m-3 m\right)$. Unidentified peaks are labeled with *. Arrows indicate location of expected $B 8$ peaks at these conditions (Ozawa et al., 2011). Inset: A conventional Mössbauer spectrum of Mw94 before heating at 1 bar (Wicks, 2013), with two example fits (no $\mathrm{Fe}^{3+}$, green, and $5 \% \mathrm{Fe}^{3+}$, red.) 
Volumes of cubic Mw94 were refined using at least three of the following four reflections: 111, 200, 220, and 331. hcp-Fe volumes were refined using at least 6 of the 8 following reflections: 100, 200, 101, 102, 110, 103, 200, and 112 . $B 2-\mathrm{NaCl}$ volumes were refined using at least 5 of the 6 following reflections: $100,110,111,200,210$, and 211. Neon volumes were determined from at least one of the two reflections: 111, 200. Rhombohedral Mw94 volumes were refined from at least 3 of the 5 following reflections: 003, 101, 102, 104, and 110 .

The B2-NaCl thermal equation of state of Fei et al. (2007b) was used to determine pressure in the unbuffered experiment, and to compare that dataset to the buffered experiment, because each contained an intimate mixture of $\mathrm{NaCl}$ and Mw94. Pressures in the buffered experiment were determined using the unit cell volume of $h c p$-Fe. We used the equation of state of $h c p$-Fe given by Dewaele et al. (2006), and the thermal pressure given by Murphy et al. (2011). The difference between the two pressure scales is small, with a resulting pressure increase ranging from 0.01 to $0.4 \mathrm{GPa}$ for the Murphy et al. (2011) values.

The greatest source of error in these measurements comes from the temperature determination. Past studies have analyzed these sources of error in great detail for experiments conducted in the laser-heated diamond-anvil cell (e.g. Heinz and Jeanloz, 1987; Kavner and Jeanloz, 1998; Panero and Jeanloz, 2001; Shim et al., 2000; Shen et al., 2001; Benedetti and Loubeyre, 2004; Noguchi et al., 2013). The errors depend heavily on the individual experiments, with cited temperature uncertainties ranging from a few percent to 10 percent. Considering the measured range of standard deviations from multiple measurements for each XRD pattern collected in our study (between 1 and $104 \mathrm{~K}$ ) and previous reports suggesting an accuracy of such measurements to be between about 100 and 200 K (Shen et al., 2001; Sturhahn and Jackson, 2007; Noguchi et al., 2013), we report a temperature uncertainty of $100 \mathrm{~K}$.

The error in pressure is a function of the uncertainty in both the volume and temperature of the in situ pressure calibrant ( $h c p-\mathrm{Fe}$ or $B 2-\mathrm{NaCl}$, in this case). However, in determining the correct error assignments for the equation of state fitting, we made adjustments to ensure that errors were not double-counted. 
Calculated volumes and pressures of the buffered and unbuffered datasets are presented in Tables D.8 and D.9, respectively.

\section{Results}

\subsection{Phase identification}

In the $P-T$ range of study, we identified cubic Mw94 at high temperature, and rhombohedral or a mixture of rhombohedral and cubic Mw94 at room temperature. We interpret the mixture to be a result of incomplete backtransformation of the cubic to rhombohedral phase on quench. We plot our phase identifications in Figure 2. In the diffraction patterns of the buffered experiment, all peaks could be assigned to known phases in the sample chamber ( $\mathrm{Mw} 94, \mathrm{NaCl}, \mathrm{Fe}, \mathrm{Ne})$. In the unbuffered experiment, there were a few weak peaks that could not be assigned to known phases of $\mathrm{Mw} 94, \mathrm{NaCl}$, or Fe. We will return to this topic later in our discussion of stoichiometry. Our cold compression points are shown in gray, bracketing the room temperature cubic-rhombohedral transition between 13 and 24 GPa.

As we did not identify the $B 8$ structure in our $P-T$ range of study, we observe that the addition of $\mathrm{Mg}$ to $\mathrm{FeO}$ stabilizes the $B 1$ phase with respect to the $B 8$ phase at these conditions. At $300 \mathrm{~K}$, our data bracket the $B 1$ to rhombohedral transition indicated for $\mathrm{FeO}$, but our data coverage at room temperature is not high enough to make comparisons. At high temperature, our observation of only the cubic structure is inconsistent with those of Kondo et al. (2004) and Ohta et al. (2014). Kondo et al. (2004) reports an expansion of the stability field of rhombohedrally-structured (Mg,Fe)O up to $2000 \mathrm{~K}$ at $120 \mathrm{GPa}$ for $\left(\mathrm{Mg}_{0.05} \mathrm{Fe}_{0.95}\right) \mathrm{O},\left(\mathrm{Mg}_{0.1} \mathrm{Fe}_{0.9}\right) \mathrm{O}$ and $\left(\mathrm{Mg}_{0.2} \mathrm{Fe}_{0.8}\right) \mathrm{O}$ sandwiched between corundum disks, regardless of composition. Ohta et al. (2014) reported a similar rhombohedral phase boundary for $\left(\mathrm{Mg}_{0.2} \mathrm{Fe}_{0.8}\right) \mathrm{O}$ prepared with silica glass as a pressure medium. The use of a neon pressure medium in our experiments could be one explanation for the discrepancy. 


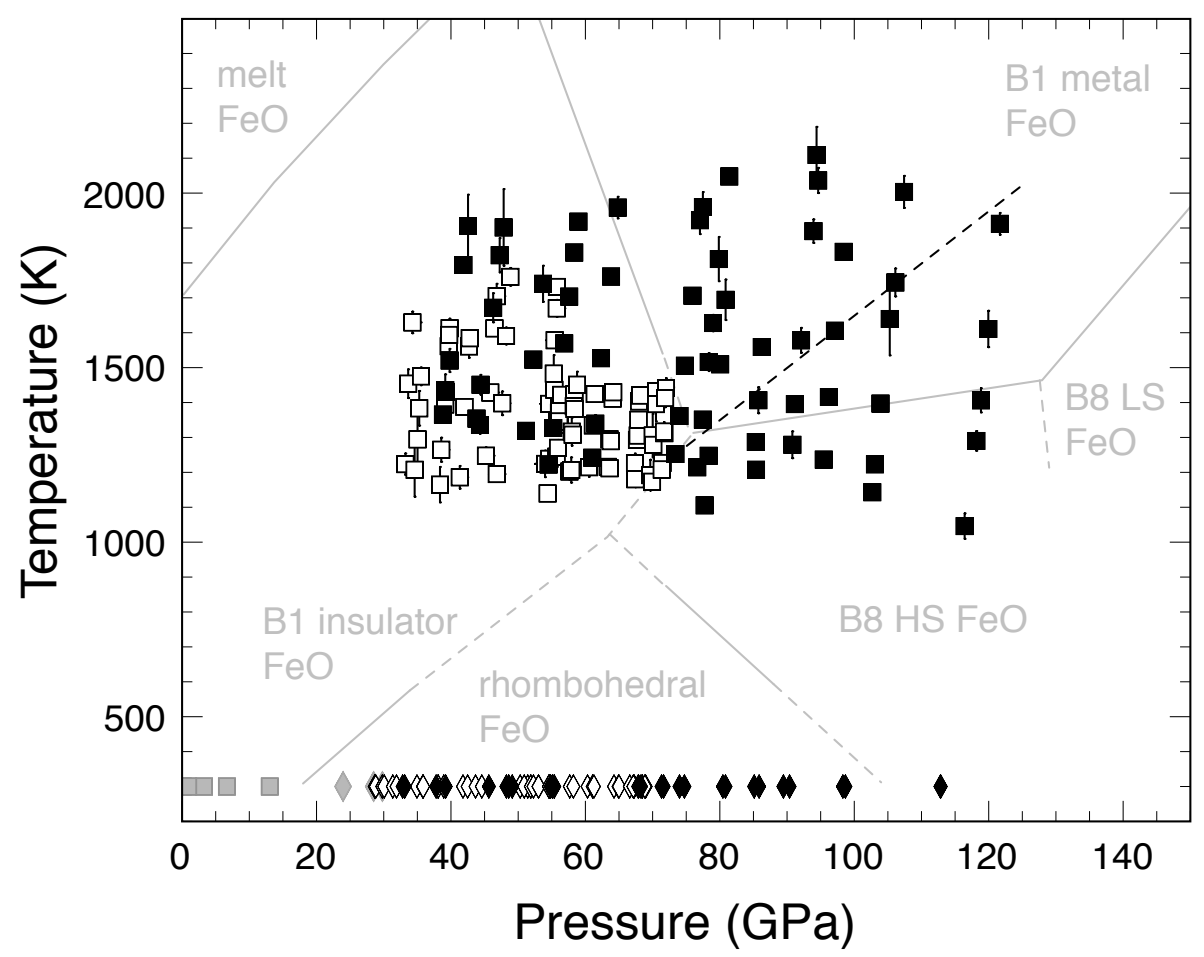

Figure 2: Phase identification of $\left(\mathrm{Mg}_{0.06} \mathrm{Fe}_{0.94}\right) \mathrm{O}$ in $P-T$ space. $\left(\mathrm{Mg}_{0.06} \mathrm{Fe}_{0.94}\right) \mathrm{O}$ is cubic (unbuffered $\square$, buffered $\mathbf{\square}$ ) at high temperature and rhombohedral (unbuffered $\diamond$, buffered $\downarrow$ ) at room temperature. Before-heating points from the buffered experiment are shown below $25 \mathrm{GPa}$ in gray $(\square, \downarrow)$. Light gray lines and text: the latest phase diagram of wüstite (Fei and Mao, 1994; Fischer et al., 2011a,b; Kondo et al., 2004; Ozawa et al., 2010, 2011). Pressures shown here in the buffered experiment used $h c p$-Fe as a pressure marker, while pressures in the unbuffered experiment used $B 2-\mathrm{NaCl}$. Black dashed line: $B 1$-rhombohedral phase boundary for iron $(\mathrm{Mg}, \mathrm{Fe}) \mathrm{O}$ of varying composition (Kondo et al., 2004). Error bars shown represent standard deviation of individual temperature measurements.

\subsection{Thermal equation of state fitting using MINUTI}

The buffered and unbuffered $P-V-T$ data of Mw94 were fit using an opensource thermal equation of state fitting routine (seos) within the MINeral physics UTIility software package, MINUTI version 1.1.0 (Sturhahn, 2015). We describe the thermal equation of state and parameter fitting here.

The free energy or Helmholtz energy is written as the sum of a term describ- 
225 by

226 by by

ing the elastic deformation $F_{e l}$ and a term describing the lattice vibrations

$$
\begin{array}{r}
F(V, T)=F_{e l}(V)+F_{t h}(V, T)-F_{t h}\left(V, T_{0}\right)= \\
F_{e l}(V)-k_{B} T \ln Z_{t h}(V, T)+k_{B} T_{0} \ln Z_{t h}\left(V, T_{0}\right)
\end{array}
$$

The partition function $Z$ gives the contribution of lattice vibrations and is expressed by the phonon density of states

$$
\ln Z_{t h}(V, T)=-\int \ln \left(2 \sinh \frac{\omega}{2 k_{B} T}\right) D(\omega, V) d \omega .
$$

The elastic part of (1) can be selected to be of type Birch-Murnaghan, Vinet, or logarithmic. In this study, we used a Birch-Murnaghan type, which is given

$$
\begin{array}{r}
F_{e l}(V)=\frac{9}{2} K_{0} V_{0} f^{2}\left\{1+f\left(K_{0}^{\prime}-4\right)\right\} \\
\text { with } \quad f=\frac{1}{2}\left\{\left(\frac{V_{0}}{V}\right)^{2 / 3}-1\right\}
\end{array}
$$

In these relations, $V_{0}$ is the volume at zero pressure, $K_{0}$ is the isothermal bulk modulus at zero pressure, and $K_{0}^{\prime}$ is the pressure derivative of the isothermal bulk modulus at zero pressure. All values are assumed at a reference temperature $T_{0}(300 \mathrm{~K}$, in this case). Therefore at the reference temperature the EOS is given by the elastic part only.

The seos program uses the Debye approximation for the phonon density of states which features one volume-dependent parameter, the Debye temperature $\Theta$. For $\omega \leq k_{B} \Theta$

$$
D(\omega)=\frac{9}{k_{B} \Theta}\left(\frac{\omega}{k_{B} \Theta}\right)^{2} .
$$

With this approximation, the free energy of the Debye phonon gas is given

$$
F_{t h}(V, T)=3 k_{B} T \ln \left(2 \sinh \frac{\Theta}{2 T}\right)-k_{B} T I\left(\frac{\Theta}{T}\right)-\frac{3}{8} k_{B} \Theta
$$

with

$$
I(t)=\frac{3}{t^{3}} \int_{0}^{t} \frac{x^{3} d x}{\mathrm{e}^{x}-1}
$$


The thermal pressure now takes the Mie-Grüneisen-Debye form

$$
p_{t h}(V, T)=-\left(\frac{\partial F_{t h}}{\partial V}\right)_{T}=\frac{\gamma}{V}\left(3 k_{B} T I\left(\frac{\Theta}{T}\right)+\frac{9}{8} k_{B} \Theta\right)
$$

where $\gamma=-\partial \ln \Theta / \partial \ln V$ is the Debye-Grüneisen parameter which is expressed by the seos program using a scaling law

$$
\gamma(V)=\gamma_{0}\left(\frac{V}{V_{0}}\right)^{q}
$$

where $\gamma_{0}, q$, and $V_{0}$ are inputs to the program. The expression for the Debye temperature follows via integration of $\gamma=-\partial \ln \Theta / \partial \ln V$ to result in

$$
\Theta(V)=\Theta_{0} \exp \left[\frac{\gamma_{0}-\gamma(V)}{q}\right],
$$

where $\Theta_{0}$ is an input to the seos program. For the data sets presented here, $q$ was fixed to 0.5. The Debye temperature, $\Theta_{0}$, was fixed to $426 \mathrm{~K}$, calculated from the measured Debye velocity of the starting material according to the following relation:

$$
\Theta_{0}=\frac{h}{k}\left(\frac{3 N_{A} \rho}{4 \pi \mu}\right)^{1 / 3} V_{D}
$$

where $h$ is Planck's constant, $k$ is the Boltzmann constant, $N_{A}$ is Avogadro's Number, $\mu$ is the reduced mass, $\rho=5.94 \pm 0.02 \mathrm{~g} / \mathrm{cc}$, and $V_{D}=3.075 \pm 0.014$ $\mathrm{km} / \mathrm{s}$ (Wicks, 2013). In this experiment, the equation of state fitting is not sensitive to the Debye temperature, as the temperatures in this experiment are much greater than those of the calculated Debye temperature.

For a given pressure $p$ and temperature $T$, the volume is calculated by solving the thermal EOS

$$
p=-\frac{\partial F_{e l}}{\partial V}+p_{t h}(V, T)-p_{t h}\left(V, T_{0}\right)
$$

Input data are specified as sets $\left\{p_{i}, V_{i}, T_{i}, \delta p_{i}, \delta V_{i}, \delta T_{i}\right\}$ consisting of pressure, volume, temperature, and their uncertainties. The EOS is fitted to these data by variation of parameters by minimizing the normalized mean-square deviation. In seos, some number of the fit parameters may have priors with uncertainties. 
The weights are determined by uncertainties of the data (see Appendix A for details).

If data and priors constrain the fit parameters reasonably well a solution with minimal reduced $\chi^{2}$ is obtained. These optimal parameters have errors related to data variation and prior uncertainties. The errors are estimated as variances (square errors) by Equation A.3. We report the fit-parameter correlation matrix, $\sigma_{j j^{\prime}}$, for each fitting result in the Appendix. The volume $V$ is calculated based on the EOS, Eq. 3, for various pressures and temperatures as specified in the standard input file. If fit parameters are defined, the temperature-reduced volumes $V_{r i}$ are calculated from the data $\left\{p_{i}, V_{i}, T_{i}\right\}$ as

$$
V_{r i}=V_{i}-V\left(p_{i}, T_{i}\right)+V\left(p_{i}, T_{0}\right)
$$

where $T_{0}$ is the specified reference temperature. A plot of $V\left(p_{i}, T_{0}\right)$ and $V_{r i}$ versus pressure provides an easier visual assessment of deviations between data and model (see examples in Section 3). The equation of state parameters and their associated uncertainties are described in detail in Appendix B.

Other features, such as F-f plots are also determined from seos (Sturhahn, 2015), however are not reported in this paper. The seos executable also features a spin crossover form of an equation of state that determines spin contributions (Chen et al., 2012).

With the best-fit parameters obtained from the thermal equation of state fitting and the fit-parameter correlation matrix, the following parameters can be calculated at a specified temperature over a specified pressure range: isothermal bulk modulus $K_{T}$, adiabatic seismic velocity $V_{\phi}$, and thermal expansion coefficient $\alpha$, with uncertainties reflecting the reported correlations of the fitted parameters.

\subsection{Dataset with in-situ Fe metal buffer \\ The equation of state parameters of both cubic and rhombohedral $\left(\mathrm{Mg}_{0.06} \mathrm{Fe}_{0.94}\right) \mathrm{O}$ of the buffered dataset, 38-122 GPa, were fit using pressures given by the equa- tion of state of hcp-Fe (Dewaele et al., 2006; Murphy et al., 2011). Equation of}


Table 1: Equation of state parameters of cubic and rhombohedrally-structured $\left(\mathrm{Mg}_{0.06} \mathrm{Fe}_{0.94}\right) \mathrm{O}$ for the buffered dataset using $h c p$-Fe as an internal pressure marker. Room temperature parameters correspond to a Birch-Murnaghan equation of state, while thermal parameters correspond to the Mie-Grüneisen equation of state. * Denotes numbers that were fixed in the fitting.

\begin{tabular}{lll}
\hline \hline & $B 1-\mathrm{Mw} 94$ & $r$-Mw94 \\
\hline$V_{0}\left(\AA^{3} /\right.$ atom $)$ & $9.92 \pm 0.04$ & $9.97 \pm 0.11$ \\
$K_{0 T}(\mathrm{GPa})$ & $197.4 \pm 6.5$ & $184 \pm 16$ \\
$K_{0 T}^{\prime}$ & $2.79 \pm 0.09$ & $2.98 \pm 0.25$ \\
$\theta_{0}(\mathrm{~K})$ & $426^{*}$ & \\
$\gamma_{0}$ & $1.72 \pm 0.08$ & \\
$\mathrm{q}$ & $0.50^{*}$ & \\
reduced $\chi^{2}$ & $1.07 \pm 0.13$ & $2.84 \pm 0.51$ \\
\hline
\end{tabular}

Fitting with a Birch-Murnaghan equation of state yields $V_{0}=9.92 \pm 0.04 \AA^{3} /$ atom, $K_{0 T}=197.4 \pm 6.5 \mathrm{GPa}$, and $K_{0 T}^{\prime}=2.79 \pm 0.09$. Using the high temperature Mie-Grüneisen formalism, the fitted $\gamma_{0}$ was $1.72 \pm 0.08$. The rhombohedral Mw94 phase was also fit to a Birch-Murnaghan EOS, yielding the parameters $V_{0}=9.97 \pm 0.11 \AA^{3} /$ atom, $K_{0 T}=184 \pm 16 \mathrm{GPa}$, and $K_{0 T}^{\prime}=2.98 \pm 0.25$.

Figure 3 shows the results from this buffered experiment, showing volume as a function of pressure and temperature. Also shown are the volumes measured as we compressed the cell before heating. We did not include them in the fit, as they were data collected without annealing. Near room-pressure, the steeper $\partial V / \partial P$, i.e. lower $K_{0 T}$, is more consistent with a (magnesio)wüstite containing 2-5\% vacancies (Zhang, 2000; Jacobsen et al., 2002). Projection of the high temperature data to a reference temperature of $300 \mathrm{~K}$ and associated residuals allows for visualization of goodness-of-fit (Equation 12, Figure 5a).

As the Mw94 sample pellet in the buffered experiment also contained a mixture of $\mathrm{NaCl}$, this buffered dataset was also fit using pressures given by the equation of state of $B 2-\mathrm{NaCl}$ (Table 2). When using pressures given by the equation of state of $\mathrm{NaCl}$ (Fei et al., 2007b), the fitted $V_{0}=9.92 \pm 0.03 \AA^{3} /$ atom, $K_{0 T}=199.8 \pm 5.3 \mathrm{GPa}, K_{0 T}^{\prime}=2.67 \pm 0.07$, and $\gamma_{0}=1.17 \pm 0.06$. 


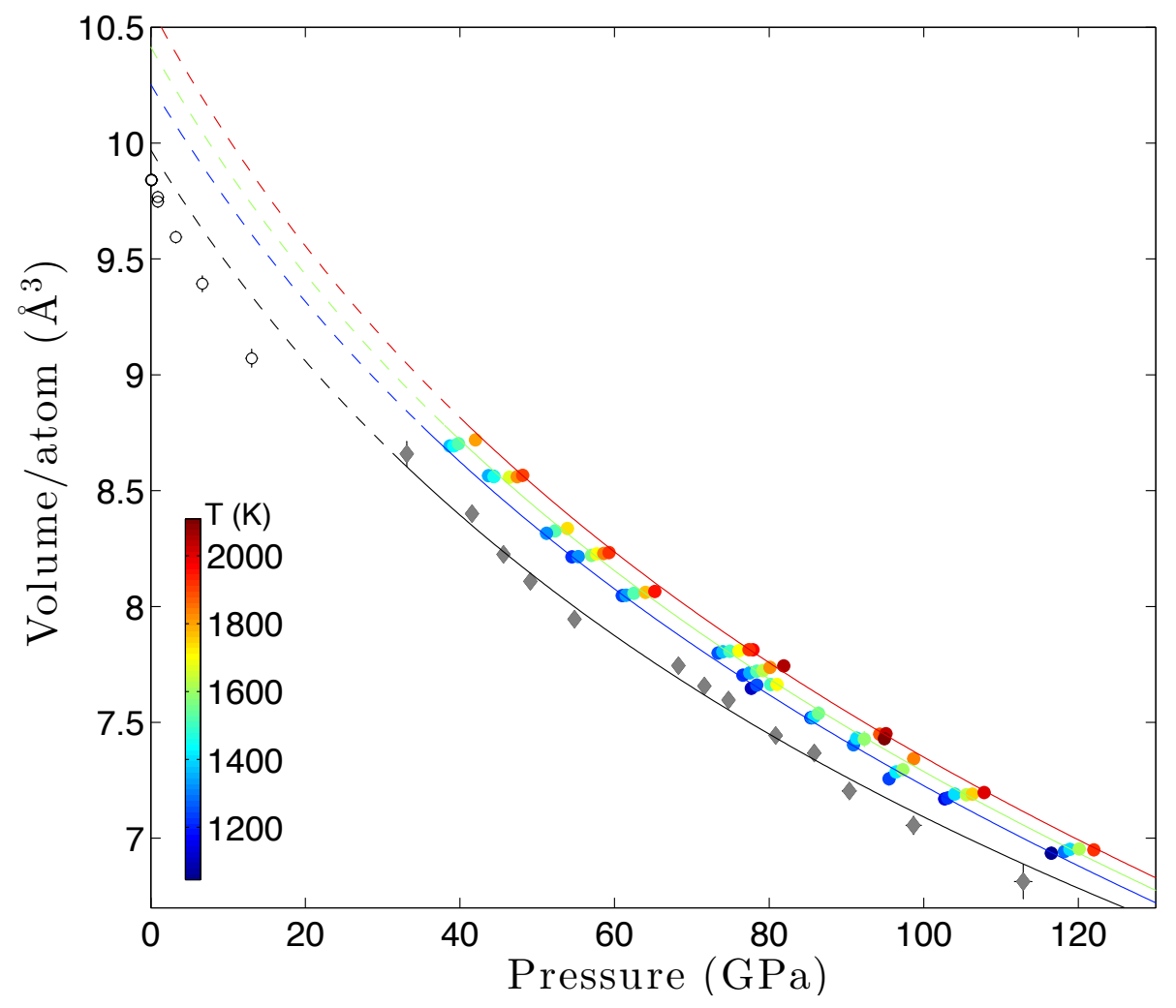

Figure 3: $P-V-T$ data and isotherms of $1200 \mathrm{~K}, 1600 \mathrm{~K}$, and $2000 \mathrm{~K}$ of $B 1$-structured $\left(\mathrm{Mg}_{0.06} \mathrm{Fe}_{0.94}\right) \mathrm{O}$ in the buffered experiment (Table 1). Pressures were determined using the equation of state of Fe (Dewaele et al., 2006; Murphy et al., 2011). Gray diamonds show rhombohedral $\left(\mathrm{Mg}_{0.06} \mathrm{Fe}_{0.94}\right) \mathrm{O}$ at room temperature, and the black line is the $300 \mathrm{~K}$ fit to these data, reduced $\chi^{2}=1.07$ (Equation 12). Open circles: pre-heating data points at pressures determined by the equation of state of $B 1-\mathrm{NaCl}$ (JCPDS 5-0628). Fitting residuals and data points projected to reference temperature of $300 \mathrm{~K}$ are shown in Figure 5a.

\subsection{Dataset with no buffer}

The equation of state of the unbuffered dataset (30-70 GPa) was fit using pressures given by the equation of state of $\mathrm{B} 2-\mathrm{NaCl}$ (Table 2). Fitting to a Birch-Murnaghan EOS yields $V_{0}=9.75 \pm 0.04 \AA^{3} /$ atom, $K_{0 T}=237 \pm 10 \mathrm{GPa}$, $K_{0 T}^{\prime}=2.26 \pm 0.18$, and $\gamma_{0}=1.34 \pm 0.11$.

Consideration of the fitted parameters of the unbuffered dataset at face value 
Table 2: Equation of state parameters of cubic $\left(\mathrm{Mg}_{0.06} \mathrm{Fe}_{0.94}\right) \mathrm{O}$ for the buffered and unbuffered datasets using $B 2-\mathrm{NaCl}$ as an internal pressure marker. Room temperature parameters correspond to a Birch-Murnaghan equation of state, while thermal parameters correspond to the Mie-Grüneisen equation of state. ${ }^{*}$ Denotes numbers that were fixed in the fitting. ${ }^{a} \mathrm{~A}$ prior of $190 \pm 15 \mathrm{GPa}$ was placed on $K_{0 T}$.

\begin{tabular}{llll}
\hline \hline & buffered & unbuffered & unbuffered (prior) \\
\hline$V_{0}\left(\AA^{3} /\right.$ atom $)$ & $9.92 \pm 0.03$ & $9.75 \pm 0.04$ & $9.87 \pm 0.03$ \\
$K_{0 T} \quad(\mathrm{GPa})$ & $199.8 \pm 5.3$ & $237 \pm 10$ & $202 \pm 6^{a}$ \\
$K_{0 T}^{\prime}$ & $2.67 \pm 0.07$ & $2.26 \pm 0.18$ & $2.89 \pm 0.13$ \\
$\theta_{0}(\mathrm{~K})$ & $426^{*}$ & $426^{*}$ & $426^{*}$ \\
$\gamma_{0}$ & $1.17 \pm 0.06$ & $1.34 \pm 0.11$ & $1.39 \pm 0.11$ \\
$\mathrm{q}$ & $0.50^{*}$ & $0.50^{*}$ & $0.50^{*}$ \\
reduced $\chi^{2}$ & $0.61 \pm 0.10$ & $0.20 \pm 0.05$ & $0.23 \pm 0.06$ \\
\hline
\end{tabular}

may lead to unphysical conclusions about the equation of state of $(\mathrm{Mg}, \mathrm{Fe}) \mathrm{O}$, often a concern of fitting a dataset with limited pressure-temperature range. Initial volume was not fixed in these fits due to the uncertainty of defect concentration, although the starting material measured volume gives a lower bound of $9.9 \AA^{3}$ /atom. Expected bulk moduli of iron-rich $(\mathrm{Mg}, \mathrm{Fe}) \mathrm{O}$ are closer to 180 GPa (Jacobsen et al., 2002), while the buffered dataset fit produced a value around $190 \mathrm{GPa}$. Such factors can be used to inform the fitting routine in the form of a prior. When fitting the unbuffered dataset with a prior placed on $K_{0 T}$ of $190 \pm 15 \mathrm{GPa}$, the resulting EOS parameters are $V_{0}=9.87 \pm 0.03 \AA^{3} /$ atom, $K_{0 T}=202 \pm 6 \mathrm{GPa}, K_{0 T}^{\prime}=2.89 \pm 0.13$, and $\gamma_{0}=1.39 \pm 0.11$. This fit results in a slight increase in the reduced $\chi^{2}$ (0.23 compared to 0.20$)$, a result of the penalty in using a prior (equation A.1). Given the limited pressure-temperature range of the unbuffered study compared to the buffered study, the equation of state fitted using such a prior on $K_{0 T}$ (Table 2) is favored. Caution should be used in extrapolating this EOS beyond the PT conditions studied here.

Figure 4 shows the results from the unbuffered experiment, showing volume change of $\left(\mathrm{Mg}_{0.06} \mathrm{Fe}_{0.94}\right) \mathrm{O}$ as a function of pressure and temperature, using $\mathrm{NaCl}$ as a pressure marker. A visual comparison of the two fits (with and without a prior on $K_{0 T}$ ) can be seen in Figure 6 showing that in the region of data 


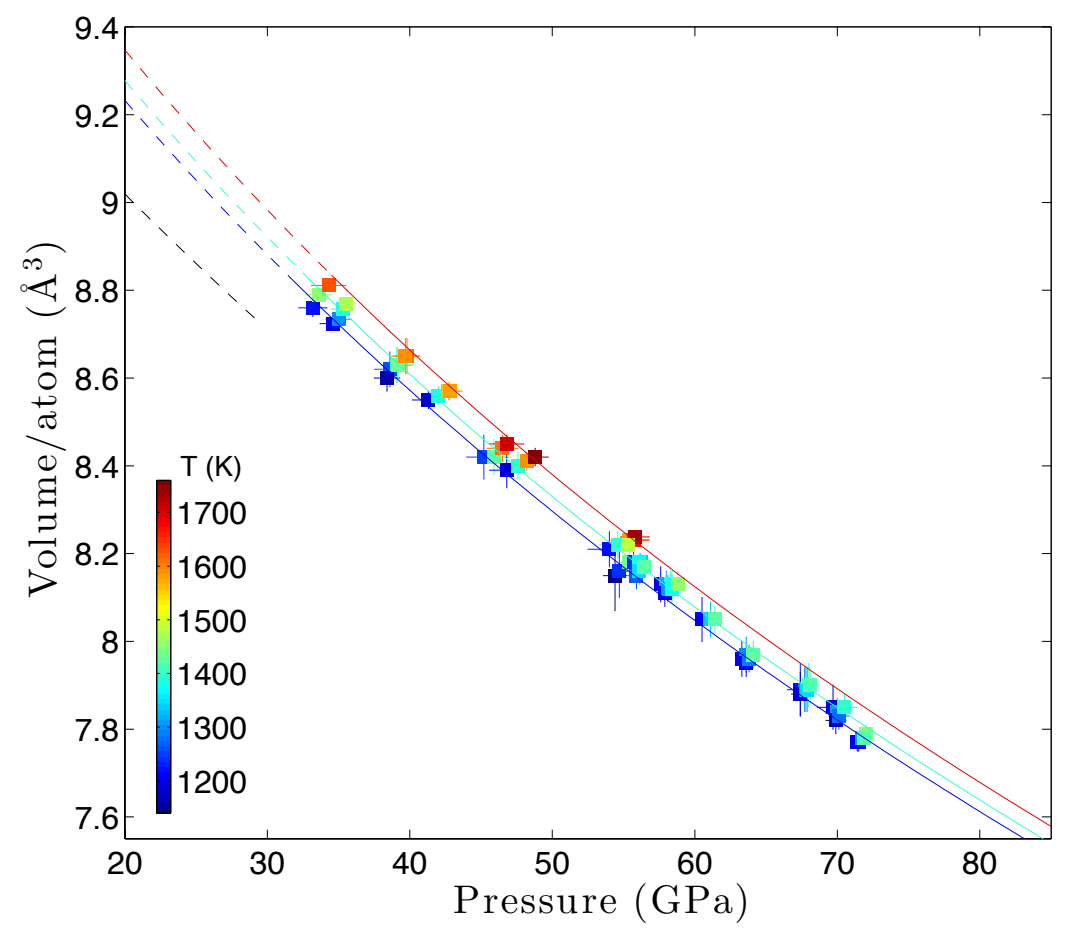

Figure 4: $P-V-T$ data and isotherms at $1200 \mathrm{~K}, 1400 \mathrm{~K}$, and $1700 \mathrm{~K}$ of $B 1$-structured $\left(\mathrm{Mg}_{0.06} \mathrm{Fe}_{0.94}\right) \mathrm{O}$ in the unbuffered experiment. Equation of state parameters corresponding to these curves are those using a prior of $K_{0 T}=190(15) \mathrm{GPa}$ in Table 2. The $300 \mathrm{~K}$ isotherm for this EOS is also shown up to $30 \mathrm{GPa}$. Pressures were determined using the equation of state of $B 2-\mathrm{NaCl}$ (Fei et al., 2007b) (reduced $\chi^{2}=0.23$ ). Fitting residuals and data points projected to reference temperature of $300 \mathrm{~K}$ are shown in Figure 5b. coverage, the two fits agree with each other very well.

\section{Discussion}

\subsection{Phase diagram of iron-rich $(\mathrm{Mg}, \mathrm{Fe}) \mathrm{O}$}

The phase identifications presented in Figure 2 are consistent with a previous result in that there is no observable $B 8$-structured $\left(\mathrm{Mg}_{0.06} \mathrm{Fe}_{0.94}\right) \mathrm{O}$ in the pressure and temperature range studied (Kondo et al., 2004). Our study, however, 
disagrees with previous reports of the location of the rhombohedral-cubic phase boundary of iron-rich (Mg,Fe)O at high temperature. Where Kondo et al. (2004) find a transition of rhombohedral to cubic $\left(\mathrm{Mg}_{0.1} \mathrm{Fe}_{0.9}\right) \mathrm{O}$ and $\left(\mathrm{Mg}_{0.05} \mathrm{Fe}_{0.95}\right) \mathrm{O}$ at 1100 to $1500 \mathrm{~K}$ in the pressure range of 70 to $100 \mathrm{GPa}$, we find no evidence of rhombohedral $\left(\mathrm{Mg}_{0.06} \mathrm{Fe}_{0.94}\right) \mathrm{O}$ at the high temperatures explored in our study (Figure 2).

In comparison to the phase diagram of $\mathrm{FeO}$, we show that substitution of $\mathrm{Mg}$ into $\mathrm{FeO}$ expands the stability field of the rhombohedral phase with respect to the $B 8$ phase.

Decomposition of the $(\mathrm{Mg}, \mathrm{Fe}) \mathrm{O}$ solid solution at high $P-T$ conditions has been reported (Dubrovinsky et al., 2000). More recently, $\left(\mathrm{Mg}_{0.05} \mathrm{Fe}_{0.95}\right) \mathrm{O}$ was found to decompose into $\mathrm{B} 8 \mathrm{FeO}$ and $\left(\mathrm{Mg}_{0.06} \mathrm{Fe}_{0.94}\right) \mathrm{O}$ in a diffraction pattern at $123 \mathrm{GPa}$, after heating up to $2800 \mathrm{~K}$. This sample was also recovered to 1 bar for ATEM measurements and shown to have these two distinct phases (Ohta et al., 2014). Such compelling evidence for a high P-T experiment on Mw95 at pressures around $70 \mathrm{GPa}$ was not presented, although Mw95 was suggested to have decomposed (Ohta et al., 2014). The starting composition we investigated in this study is one of their suggested reaction products, Mw94. Nevertheless, we searched our diffraction patterns for such evidence and do not see end member $\mathrm{FeO}$ in any of our diffraction patterns. It is possible that Mw94 does decompose, but at higher $\mathrm{P}-\mathrm{T}$ conditions than what we sampled or that $(\mathrm{Mg}, \mathrm{Fe}) \mathrm{O}$ forms a complete solid solution up to at least $94 \%$ FeO.

\subsection{Equations of state for iron-rich $(\mathrm{Mg}, \mathrm{Fe}) \mathrm{O}$}

The isothermal bulk modulus $K_{0 T}$ resulting from the equation of state fitting to the high-PT data of the buffered and unbuffered data sets is at the upper end of that predicted for nearly stoichiometric ( $\mathrm{Mg}, \mathrm{Fe}) \mathrm{O}$ (Jacobsen et al., 2002). Previous work shows that the bulk modulus of $(\mathrm{Mg}, \mathrm{Fe}) \mathrm{O}$ decreases with increasing Fe content, from $\sim 160 \mathrm{GPa}$ for the MgO end member to $150 \mathrm{GPa}$ for $\mathrm{Fe}_{0.95} \mathrm{O}$, likely due to increasing defect content. Conversely, stoichiometric examples show the opposite trend- bulk modulus increases with increasing $\mathrm{Fe}$ 
content, up to $180 \mathrm{GPa}$ for stoichiometric FeO (Jacobsen et al., 2002). All of our fits fall on the high side of this range of bulk moduli, but are admittedly not very well constrained by a compression study such as this one, with no annealed data at low pressure.

In Figure 6, we compare the data and thermal equations of state determined for the buffered and unbuffered experiments using their common internal pressure marker, the $B 2-\mathrm{NaCl}$ pressure scale (Fei et al., 2007b). We do not discern an effect of buffering the composition on the equation of state of the Mw94 sample investigated here.

As a more quantitative measure, two datasets can be compared by using one dataset's results as a prior on the other. When fitting the unbuffered dataset, using buffered values and associated error bars as priors, the resulting reduced chi-squared is $0.27 \pm 0.06$, not worse than that of the fit without said priors. As a result, the two datasets are not distinguishable in their overlapping $\mathrm{P}-\mathrm{T}$ range. The values reported in Table 2 show that some of the fitted parameters are consistent within error bars, with the exception of $K_{0 T}$ and $K_{0 T}^{\prime}$. A discrepancy in these two parameters, in turn, is not surprising, given the limited compression range of the unbuffered dataset, especially in the low pressure range where $K_{0 T}$ and $K_{0 T}^{\prime}$ are most tightly constrained.

In Figure 7, error ellipses showing the tradeoff between equation of state parameters $K_{0 T}^{\prime}$ versus $\gamma_{0}$ and $V_{0}$ versus $K_{0 T}$ demonstrate the overlap in thermal EOS parameters between buffered and unbuffered datasets when using the same internal pressure marker $(\mathrm{B} 2-\mathrm{NaCl})$.

Another assessment is the level of compatibility in the thermal EOS parameters between the buffered Mw94 experiment (this study) and that of wüstite (Fischer et al., 2011b). As both experiments were conducted with an in situ $\mathrm{Fe}$ metal buffer/pressure marker, any measurable differences should be due to the incorporation of $\mathrm{Mg}$ into wüstite. When evaluating the buffered $\left(\mathrm{Mg}_{0.06} \mathrm{Fe}_{0.94}\right) \mathrm{O}$ dataset, using the FeO equation of state values from Fischer et al. (2011b) as priors $\left(\gamma=1.42(5), K_{0 T}=149(1), K_{0 T}^{\prime}=3.60(4)\right)$, the resulting reduced chisquared increased from 1.07 to $1.74 \pm 0.16$, indicating that the two datasets are 
not compatible.

From the equation of state parameters reported in Table 1, the thermal expansion coefficient $\alpha$ at specified output temperatures can be computed (Eq. B.5) with uncertainties (Eqs. A.5, B.7). Figure 8 shows the thermal expansion coefficient $\alpha$ (Equation B.5) determined from the buffered dataset calculated at $1500 \mathrm{~K}$ and $3800 \mathrm{~K}$ over the pressure range 0-140 GPa. We chose the value of $3800 \mathrm{~K}$, because the melting temperature of wüstite at core-mantle boundary conditions is suggested to be about $3900 \mathrm{~K}$ (Fischer and Campbell, 2010). Also shown are the thermal expansion coefficients calculated for $\mathrm{FeO}$ which was measured up to $156 \mathrm{GPa}$ and $3100 \mathrm{~K}$ (Fischer et al., 2011b) and for MgO which was measured up to $196 \mathrm{GPa}$ and $3700 \mathrm{~K}$ (Tange et al., 2009, Fit2-Vinet). It is obvious from Figure 8 that the thermal equation of state of buffered wüstite (Fischer et al., 2011a) and buffered Mw94 using hcp-Fe as a pressure marker in each study are significantly distinct, as we discussed earlier. With this consideration, together with the Mw94 fit quality (e.g., Figure 5a) and the parameter correlations (Appendix C), we conclude that Mw94 has measurably distinct thermoelastic properties compared with those of wüstite.

\subsection{Sample Stoichiometry}

The collected Mössbauer spectrum of the starting material (Figure 1, inset) was fit using CONUSS (Sturhahn, 2000). A fit of a single $\mathrm{Fe}^{2+}$ site with an isomer shift of $1.03 \pm 0.04 \mathrm{~mm} / \mathrm{s}$ (with respect to bcc iron) and a quadrupole splitting of $1.21 \pm 0.03 \mathrm{~mm} / \mathrm{s}$ (distribution of $0.43 \pm 0.03 \mathrm{~mm} / \mathrm{s}$ ) best fit the data $\left(\chi^{2}=0.99\right)$, but does not capture the asymmetry of the doublet. The addition of a $\mathrm{Fe}^{3+}$ site with an isomer shift of $0.4 \mathrm{~mm} / \mathrm{s}$ and a quadrupole splitting of $0.3 \mathrm{~mm} / \mathrm{s}$ better (McCammon and Price, 1985) describes the spectrum visually with resulting hyperfine parameters of the ferrous site within uncertainties of the above-mentioned parameters $\left(\chi^{2}=0.95\right)$.

The discrepancy between un-annealed low pressure data ( 0 to about 13 GPa, Figure 3) and annealed high pressure measurements in the buffered experiment suggests a physical difference between cold-compressed and annealed iron-rich 
$(\mathrm{Mg}, \mathrm{Fe}) \mathrm{O}$. As mentioned, the steeper slope is more consistent with a sample containing 2-5\% vacancies (Zhang, 2000; Jacobsen et al., 2002). It has been proposed that vacancy concentrations in non-stoichiometric FeO-bearing samples are reduced with the exsolution of $(\mathrm{Fe}, \mathrm{Mg}) \mathrm{Fe}_{2} \mathrm{O}_{4}$ at high pressure and temperature, ensuring the stoichiometry of the $(\mathrm{Mg}, \mathrm{Fe}) \mathrm{O}$ phase regardless of oxygen fugacity (Zhang and Zhao, 2005; McCammon et al., 1998). It has also been proposed in the $\mathrm{FeO}$ end member that this exsolution occurs at the pressure of the magnetite to $h-\mathrm{Fe}_{3} \mathrm{O}_{4}$ transition (Fei, 1996).

It may be possible that this reaction proceeded at high temperatures in the unbuffered experiment, as the small, unidentified peaks may be attributed to a high pressure oxide phase such as $h-\mathrm{Fe}_{3} \mathrm{O}_{4}, \mathrm{MgFe}_{2} \mathrm{O}_{4}$ or $\mathrm{Fe}_{4} \mathrm{O}_{5}$ (Dubrovinsky et al., 2003; Lavina et al., 2011; Andrault and Bolfan-Casanova, 2001), Appendix E. The resulting consequences for sample chemistry are unclear. It could be possible that an exsolved oxide is either more, less, or equally iron-rich than the remaining material, leaving behind a sample that is less, more, or equally iron-rich to the starting composition. Similarly, we assume that the buffered experiment is achieved by the addition of $\mathrm{Fe}^{0}$ for every $\mathrm{Fe}^{3+}$, assured by the lack of excess peaks. In the end member scenario, the assumption of $5 \%$ vacancies would create a sample enriched in iron in comparison to the unbuffered experiment. As mentioned previously, the buffered and unbuffered datasets were statistically similar to each other, but inconsistent with FeO, so we conclude that resulting chemical variation between the two experiments must be small.

\subsection{Geophysical Implications}

When extrapolated to the conditions near the core-mantle boundary, at 135 GPa and $3800 \mathrm{~K}$ (e.g. Tackley, 2012), our buffered equation of state predicts a density of $\rho=8.32 \pm 0.04 \mathrm{~g} / \mathrm{cm}^{3}$, bulk modulus $K_{T}=423 \pm 8 \mathrm{GPa}$, bulk sound velocity $v_{\phi}=7.14 \pm 0.07 \mathrm{~km} / \mathrm{s}$, and thermal expansion $\alpha=2.01 \pm 0.01$ $\left(10^{-5} \mathrm{~K}^{-1}\right)$. Figure 9 shows the calculated density and bulk sound velocities at $3800 \mathrm{~K}$ of $\left(\mathrm{Mg}_{0.06} \mathrm{Fe}_{0.94}\right) \mathrm{O}$, determined from the fitted thermal equation of state. Covariance among parameters is considered in the determination of uncertainty 
(see Appendix C). Also shown are density and bulk sound velocity of $\mathrm{MgO}$ (red dotted line, Tange et al. (2009), Fit2-Vinet), wüstite (red dashed line, Fischer et al. (2011b)), bridgmanite (blue dotted line, (Tange et al., 2012, Vinet Fit)), calcium silicate perovskite (green dotted line, (Noguchi et al., 2013, Model 1)), and the bulk mantle, represented by PREM (Dziewonski and Anderson, 1981). Also shown at $135 \mathrm{GPa}$ is the range of constrained density from seismic studies of ultralow-velocity zones (Rost et al., 2006), which may contain iron-rich $(\mathrm{Mg}, \mathrm{Fe}) \mathrm{O}$.

Iron-rich $(\mathrm{Mg}, \mathrm{Fe}) \mathrm{O}$ in solid form is denser than the silicate-dominated lower mantle $\left(\mathrm{MgSiO}_{3}\right)$, but not as dense as the liquid Fe-alloy outer core (Figure 9). Our constrained value of $\alpha$ can thus be used in geodynamic models to compute the thermal buoyancy of iron-rich $(\mathrm{Mg}, \mathrm{Fe}) \mathrm{O}$, for example to model the dynamics of ULVZs (e.g. Bower et al., 2011). The bulk sound velocity of Mw94 is lower than both the lowermost mantle and the core.

Using geodynamic modeling, Bower et al. (2011) showed that chemical density anomalies of $2-8 \%$ produced ULVZs with a variety of reasonable ULVZ morphologies. In the future, these characteristic morphologies could be used to constrain composition with sufficient 2-d and 3-d seismic imaging. Other studies cite ULVZs of around 10\% density anomaly (e.g. Rost et al., 2006). If we assumed that a ULVZ was formed by entrainment of iron-rich material (such as Mw94) with ambient mantle, a 2-10\% density anomaly could be explained by 4$20 \%$ volume fraction, respectively. To match ULVZ densities, a smaller(larger) volume fraction would be required for mixing $(\mathrm{Mg}, \mathrm{Fe}) \mathrm{O}$ with a greater(smaller) Fe content.

The relative density of iron-rich $(\mathrm{Mg}, \mathrm{Fe}) \mathrm{O}$ compared to its surroundings may also be useful when interpreting seismic signatures on the core side of the coremantle boundary, which could be a reservoir of solid precipitates on the top of the core (Buffett et al., 2000). These precipitates can aid as a diffusion barrier between the core and the mantle, and thus far display seismic signatures that have been difficult to distinguish from similar features on the mantle side. 


\section{Summary}

We have determined the $P-V-T$ equation of state of $\left(\mathrm{Mg}_{0.06} \mathrm{Fe}_{0.94}\right) \mathrm{O}$ in two distinct sets of experiments: one with an Fe oxygen fugacity buffer and one without Fe. Considering the covariance of the fitted equation of state parameters using the seos module in the MINUTI software package, we have determined the level of compatibility between the buffered and unbuffered data sets of Mw94, as well as between Mw94 and wüstite, using the same pressure indicators. We find that the addition of small amounts of $\mathrm{Mg}$ causes measurable affects on the thermoelastic properties of wüstite.

We see a clear difference in the location of the phase boundary between cubic and rhombohedral iron-rich $(\mathrm{Mg}, \mathrm{Fe}) \mathrm{O}$ at high pressure and temperature, compared with previous studies. Unlike Kondo et al. (2004), we do not find rhombohedrally-structured iron-rich $(\mathrm{Mg}, \mathrm{Fe}) \mathrm{O}$ in our high temperature measurements. In addition, we also do not find the $B 8$ structure in our high temperature measurements, indicating that $\mathrm{Mg}$ stabilizes the cubic phase upon substitution into FeO (Fischer et al., 2011b).

The calculated bulk sound velocity and density from this study can be used to constrain geophysical models of ULVZs that consider an assemblage of phases that include iron-rich $(\mathrm{Mg}, \mathrm{Fe}) \mathrm{O}$.

\section{Acknowledgements}

We thank D. Zhang and C.A. Murphy for assistance with the measurements, A.S. Wolf and D.B. Bower for discussions, and NSF-EAR 0711542 and CSEDI EAR-0855815 for financial support. We thank E.E. Alp for conducting the conventional Mössbauer spectroscopy measurements at Argonne National Laboratory. This work was performed at GeoSoilEnviroCARS (Sector 13), Advanced Photon Source (APS), Argonne National Laboratory. GeoSoilEnviroCARS is supported by the National Science Foundation - Earth Sciences (EAR-1128799) and Department of Energy - Geosciences (DE-FG02-94ER14466). Use of the Advanced Photon Source was supported by the U.S. Department of Energy, 
Office of Science, Office of Basic Energy Sciences, under contract No. DEAC02-06CH11357. The gas-loading system at GSECARS and conventional Mössbauer spectroscopy laboratory are supported in part by COMPRES under NSF Cooperative Agreement EAR 06-49658. Sample synthesis was carried out in the petrological facilities at Caltech. Microprobe analyses were carried out at the Caltech GPS Division Analytical Facility (funded in part by the MRSEC Program of the NSF under DMR-0080065). Finally, we would like to acknowledge two anonymous reviewers, whose feedback helped to improve the manuscript. 

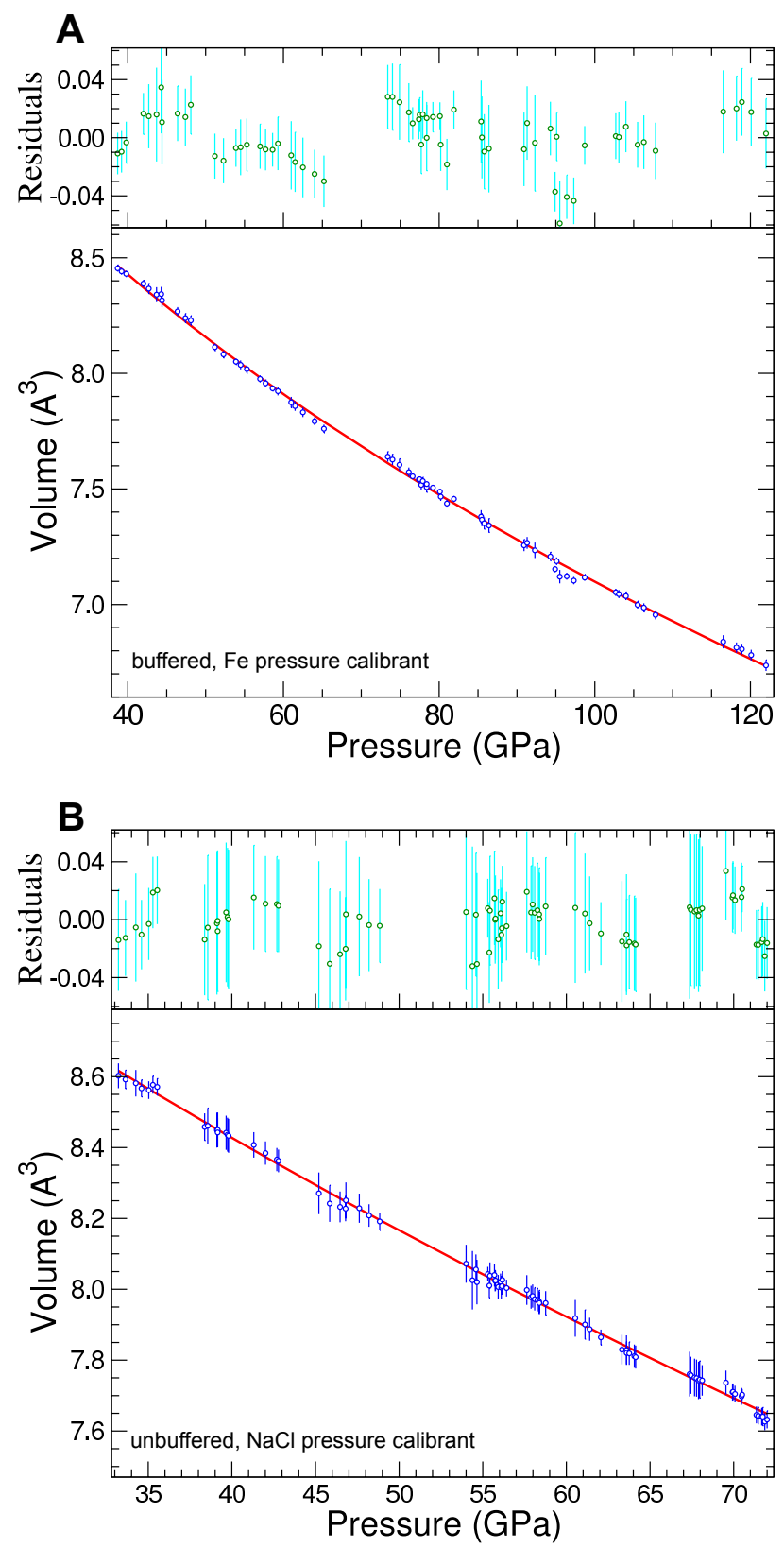

Figure 5: Fitting residuals of $\left(\mathrm{Mg}_{0.06} \mathrm{Fe}_{0.94}\right) \mathrm{O}$ and projected data at $300 \mathrm{~K}$. A) buffered dataset (reduced $\chi^{2}=1.07$ ). B) unbuffered dataset fit with a prior on $K_{0 T}=190(15) \mathrm{GPa}$ (reduced $\chi^{2}=0.23$ ). 


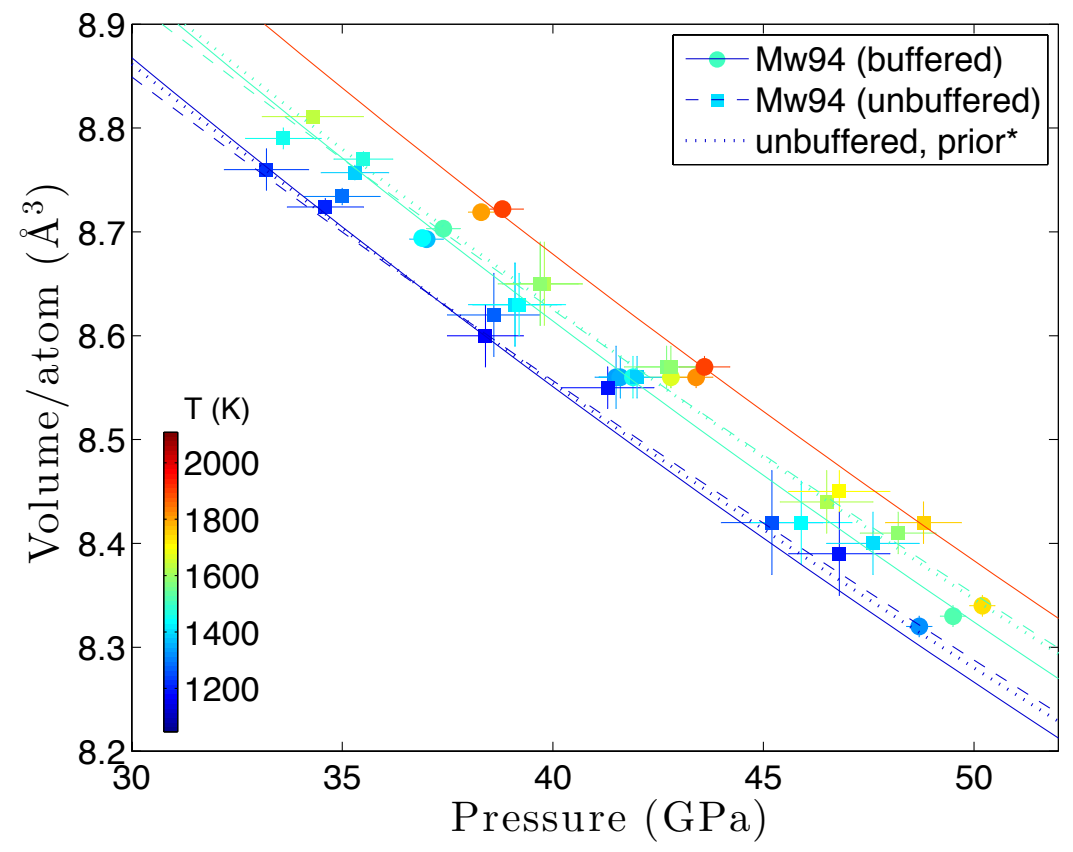

Figure 6: Overlay of data and equations of state of $\left(\mathrm{Mg}_{0.06} \mathrm{Fe}_{0.94}\right) \mathrm{O}$ in both experiments, with isotherms corresponding to $1100 \mathrm{~K}, 1500 \mathrm{~K}$, and $1900 \mathrm{~K}$. The pressure of the buffered (circles, solid lines) and unbuffered (squares, dashed and dotted lines) datasets were determined by the equation of state of their common internal pressure marker, $B 2-\mathrm{NaCl}$ (Fei et al., 2007b, Table 2). ${ }^{*}$ dotted line denotes the fit of the unbuffered dataset with a prior on $K_{0 T}$. 


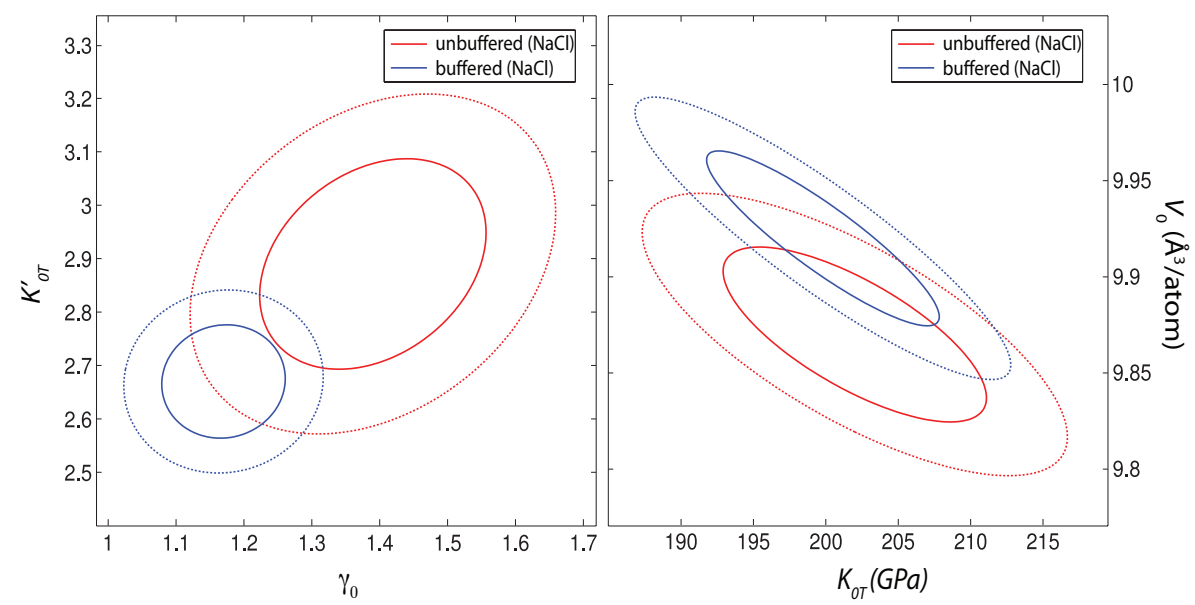

Figure 7: Error ellipses of equation of state parameters of unbuffered (red, using a prior on $K_{0}$ ) and buffered (blue) dataset using $\mathrm{B2}-\mathrm{NaCl}$ as a pressure marker (Table 2), demonstrating tradeoff of parameters $K_{0 T}^{\prime}$ versus $\gamma_{0}$ and $V_{0}$ versus $K_{0 T}$, respectively. 1 and 2- $\sigma$ standard deviations are shown with solid and dashed lines, respectively. 


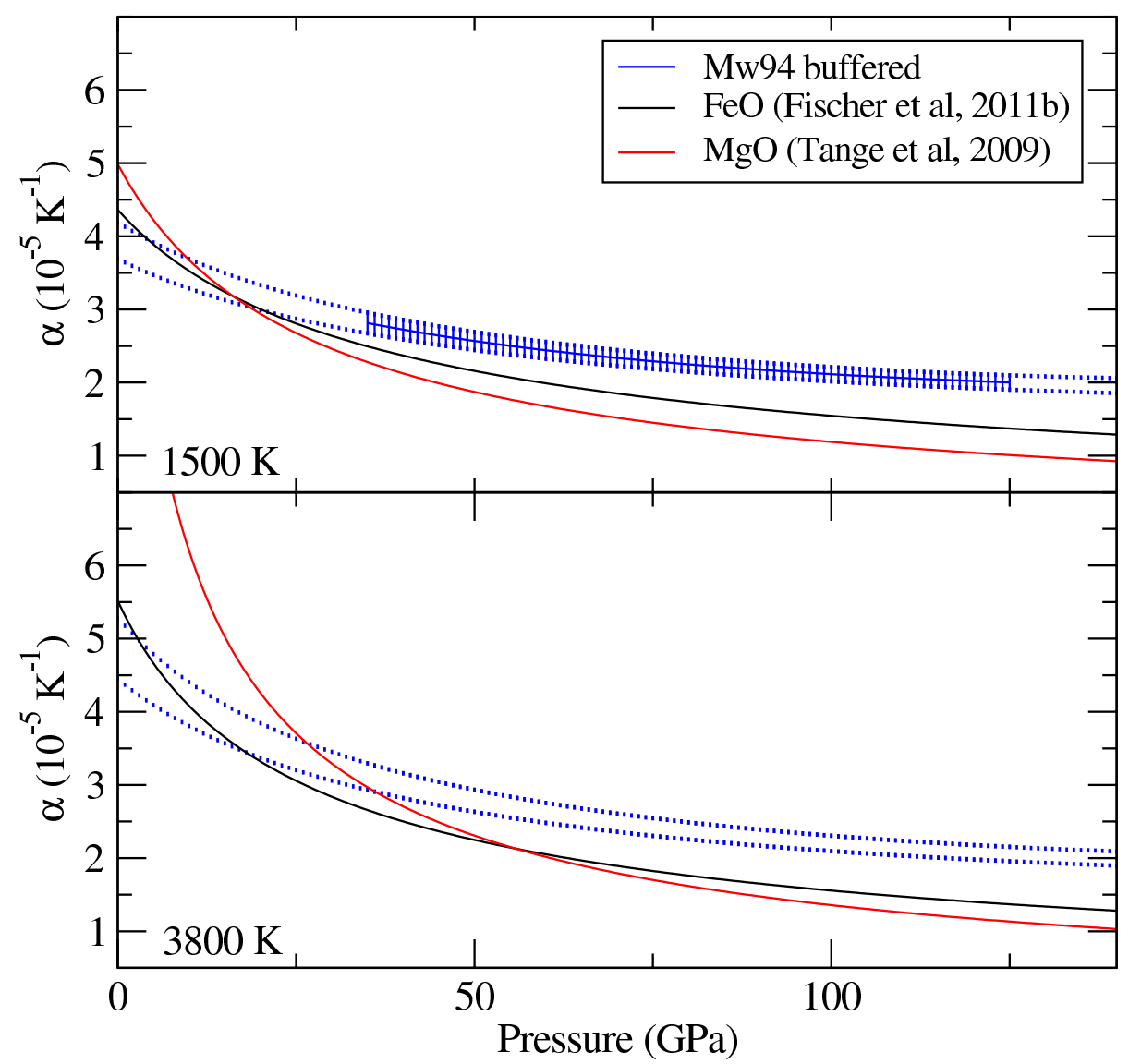

Figure 8: Linear thermal expansion coefficient ( $\alpha$, Equation B.5) calculated at $1500 \mathrm{~K}$ and $3800 \mathrm{~K}$ as a function of pressure for $\left(\mathrm{Mg}_{0.06} \mathrm{Fe}_{0.94}\right) \mathrm{O}$ with an in situ Fe buffer (blue). Error bars correspond to uncertainties calculated in seos (see Appendix). Also shown are same values calculated for $\mathrm{FeO}$ (Fischer et al., 2011b, black) and $\mathrm{MgO}$ (Tange et al., 2009, red). Dashed lines indicate regions where the values are extrapolated beyond the $P-T$ range of study. 

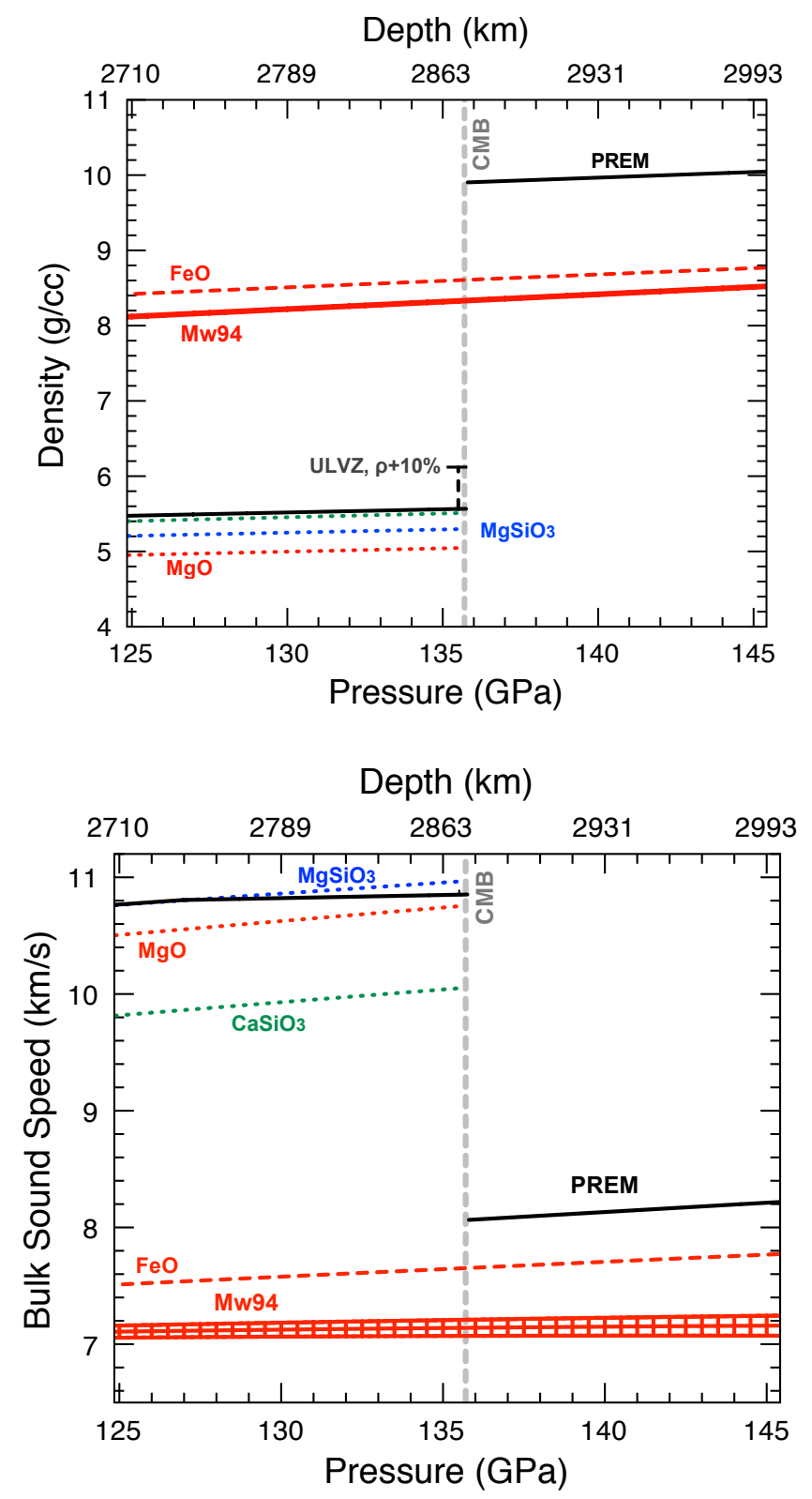

Figure 9: Density and bulk sound velocity of $\left(\mathrm{Mg}_{0.06} \mathrm{Fe}_{0.94}\right) \mathrm{O}$ calculated at $3800 \mathrm{~K}$ as a function of pressure and depth. Also shown: $\mathrm{MgO}$, (red dotted line, Tange et al., 2009), FeO (red dashed line, Fischer et al., 2011b), magnesium silicate bridgmanite (blue dotted line, Tange et al., 2012, Vinet Fit), calcium silicate perovskite, (green dotted line, Noguchi et al., 2013, Model 1), PREM (black solid line, Dziewonski and Anderson, 1981). Also shown at 135 GPa: range of constrained density from seismic studies of ultralow-velocity zones (e.g. Rost et al., 2006). 
Andrault, D., Bolfan-Casanova, N., 2001. High-pressure phase transformations in the $\mathrm{MgFe}_{2} \mathrm{O}_{4}$ and $\mathrm{Fe}_{2} \mathrm{O}_{3}-\mathrm{MgSiO}_{3}$ systems. Phys. Chem. Min. 28, 211-217.

Benedetti, L.R., Loubeyre, P., 2004. Temperature gradients, wavelengthdependent emissivity, and accuracy of high and very-high temperatures measured in the laser-heated diamond cell. High Press. Res. 24, 423-445.

Bower, D.J., Wicks, J.K., Gurnis, M., Jackson, J.M., 2011. A geodynamic and mineral physics model of a solid-state ultralow-velocity zone. Earth Planet. Sci. Lett. 303, 193-202.

Buffett, B.A., Garnero, E.J., Jeanloz, R., 2000. Sediments at the Top of Earth's Core. Science 290, 1338-1342.

Chen, B., Jackson, J.M., Sturhahn, W., Zhang, D., Zhao, J., Wicks, J.K., Murphy, C.A., 2012. Spin crossover equation of state and sound velocities of $\left(\mathrm{Mg}_{0.65} \mathrm{Fe}_{0.35}\right)$ O ferropericlase to 140 GPa. J. Geophys. Res. 117.

Dewaele, A., Datchi, F., Loubeyre, P., Mezouar, M., 2008. High-pressurehigh-temperature equations of state of neon and diamond. Phys. Rev. B 77, 094106.

Dewaele, A., Loubeyre, P., Occelli, F., Mezouar, M., Dorogokupets, P.I., Torrent, M., 2006. Quasihydrostatic Equation of State of Iron above 2 Mbar. Phys. Rev. Lett. 97, 215504.

Dubrovinsky, L., Dubrovinskaia, N., Saxena, S.K., Annersten, H., Hålenius, E., Harryson, H., Tutti, F., Rekhi, S., Le Bihan, T., 2000. Stability of Ferropericlase in the Lower Mantle. Science 289, 430-432.

Dubrovinsky, L.S., Dubrovinskaia, N., McCammon, C., Rozenber, G.K., Ahuja, R., Osorio-Guillen, J.M., Dmitriev, V., Weber, H.P., Le Bihan, T., Johansson, B., 2003. The structure of the metallic high-pressure $\mathrm{Fe}_{3} \mathrm{O}_{4}$ polymorph: experimental and theoretical study. J. Phys.: Condens. Matter 15, 7697-7706. 
Duffy, T.S., Ahrens, T.K., 1993. Thermal expansion of mantle and core materials at very high pressures. Geophys. Res. Lett. 20, 1103-1106.

Dziewonski, A.M., Anderson, D.L., 1981. Preliminary reference Earth model. Phys. Earth Planet. Inter. 25, 297-356.

Fei, Y., 1996. Crystal chemistry of $\mathrm{FeO}$ at high pressure and temperature. The Geochemical Society, Special Publication Number 5 , 243-254.

Fei, Y.., Zhang, L., Corgne, A., Watson, H., A., R., Meng, Y., Prakapenka, V., 2007a. Phase transition and metallization of $\mathrm{FeO}$ at high pressures and temperatures. Geophys. Res. Lett. 34, L17307.

Fei, Y., Mao, H.k., 1994. In Situ Determination of the NiAs Phase of FeO at High Pressure and Temperature. Science 266, 1678-1680.

Fei, Y., Ricolleau, A., Frank, M., Mibe, K., Shen, G., Prakapenka, V., $2007 b$. Toward an internally consistent pressure scale. Proc. Natl. Acad. of Sci. 104, 9182-9186.

Fischer, R.A., Campbell, A.J., 2010. High-pressure melting of wüstite. Am. Mineral. 95, 1473-1477.

Fischer, R.A., Campbell, A.J., Lord, O.T., Shofner, G.A., Dera, P., Prakapenka, V.B., 2011a. Phase transition and metallization of $\mathrm{FeO}$ at high pressures and temperatures. Geophys. Res. Lett. 38, L24301.

Fischer, R.A., Campbell, A.J., Shofner, G.A., Lord, O.T., Dera, P., Prakapenka, V.B., 2011b. Equation of state and phase diagram of FeO. Earth Planet. Sci. Lett. 304, 496-502.

Garnero, E.J., Helmberger, D.V., 1998. Further structural constraints and uncertainties of a thin laterally varying ultralow-velocity layer at the base of the mantle. J. Geophys. Res. 103, 12,495-12,509. 
Garnero, E.J., Lay, T., McNamara, A., 2007. Implications of lower-mantle structural heterogeneity for existence and nature of whole-mantle plumes. GSA Special Papers 430, 79-101.

Hammersley, A.O., Svensson, S.O., Hanfland, M., Fitch, A.N., Hausermann, D., 1996. Two-dimensional detector software: from real detector to idealized image or two-theta scan. High Press. Res. 14, 235-248.

Heinz, D.L., Jeanloz, R., 1987. Temperature measurements in the laser-heated diamond cell. Geophysical Monograph Series 39, 113-127.

Helmberger, D.V., Ni, S., Wen, L., Ritsema, J., 2000. Seismic evidence for ultralow-velocity zones beneath Africa and eastern Atlantic. J. Geophys. Res. $105,23,865-23.878$.

Hernlund, J., Jellinek, A.M., 2010. Dynamics and structure of a stirred partially molten ultralow-velocity zone. Earth Planet. Sci. Lett. 296, 1-8.

Hernlund, J., Tackley, P., 2007. Some dynamical consequences of partial melting in Earth's deep mantle. Phys. Earth Planet. Inter. 162, 149-163.

Holland, T.J.B., Redfern, S.A.T., 1997. Unit cell refinement from powder diffraction data: the use of regression diagnostics. Mineral. Mag. 61, 65-77.

Jacobsen, S.D., Reichmann, H.J., Spetzler, H., Mackwell, S.J., Smyth, J.R., Angel, R.J., McCammon, C.A., 2002. Structure and elasticity of single-crystal $(\mathrm{Mg}, \mathrm{Fe}) \mathrm{O}$ and a new method of generating shear waves for gigahertz ultrasonic interferometry. J. Geophys. Res. 107, 5867-5871.

Kantor, I., Dubrovinsky, L., McCammon, C., Steinle-Neumann, G., Kantor, A., Skorodumova, N., Pascarelli, S., Aquilanti, G., 2009. Short-range order and Fe clustering in $\mathrm{Mg}_{1-x} \mathrm{Fe}_{x} \mathrm{O}$ under high pressure. Phys. Rev. B 80, 014204.

Kavner, A., Jeanloz, R., 1998. High-pressure melting curve of platinum. J. Appl. Phys. 83, 7553-7559. 
Komabayashi, T., Hirose, K., Nagaya, Y., Sugimura, E., Ohishi, Y., 2010. Hightemperature compression of ferropericlase and the effect of temperature on iron spin transition. Earth Planet. Sci. Lett. 297, 691-699.

Kondo, T., Ohtani, E., Hirao, N., Yagi, T., Kikegawa, T., 2004. Phase transitions of (Mg,Fe)O at megabar pressures. Phys. Earth Planet. Inter. 143-144, $201-213$.

Labrosse, S., Hernlund, J., Coltice, N., 2007. A crystallizing dense magma ocean at the base of the Earth's mantle. Nature 450, 866-869.

Lavina, B., Dera, P., Kim, E., Men, Y., Downs, R., Weck, P.F., Sutton, S.R., Zhao, Y., 2011. Discovery of the recoverable high-pressure iron oxide $\mathrm{Fe}_{4} \mathrm{O}_{5}$. Proc. Natl. Acad. of Sci. 108, 17281-17285.

Lay, T., Garnero, E.J., Williams, Q., 2004. Partial melting in a thermo-chemical boundary layer at the base of the mantle. Phys. Earth Planet. Inter. 146, 441467.

Lee, C.T.A., Luffi, P., Hoink, T., Li, J., Dasgupta, R., Hernlund, J., 2010. Upside-down differentiation and generation of a 'primordial' lower mantle. Nature 463, 30-U102.

Lin, J.F., Heinz, D.L., Mao, H., Hemley, R.J., Devine, J.M., Li, J., Shen, G., 2003. Stability of magnesiowüstite in Earth's lower mantle. Proc. Natl. Acad. of Sci. $100,4405-4408$.

Lin, J.F., Struzhkin, V., Jacobsen, S., Hu, M., Chow, P., Kung, J., Liu, H., Mao, H., Hemley, R., 2005. Spin transition of iron in magnesiowüstite in the Earth's lower mantle. Nature 436, 377-380.

Mao, W.L., Lin, J.F., Liu, J., Prakapenka, V.B., 2011. Thermal equation of state of lower-mantle ferropericlase across the spin crossover. J. Geophys. Res. 38, L23308. 
Mao, W.L., Mao, H., Sturhahn, W., Zhao, J., Prakapenka, V.B., Meng, Y., Shu, J., Fei, Y., Hemley, R.J., 2006. Iron-Rich Post-Perovskite and the Origin of Ultralow-Velocity Zones. Science 312, 564-565.

McCammon, C., Peyronneau, J., Poirier, J.P., 1998. Low ferric iron content of $(\mathrm{Mg}, \mathrm{Fe}) \mathrm{O}$ at high pressures and temperatures. Geophys. Res. Lett. 25, 1589-1592.

McCammon, C.A., Price, D.C., 1985. Mössbauer spectra of $\mathrm{fe}_{x} \mathrm{o}$ (x¿0.95). Phys. Chem. Min. 11, 250-254.

Mukhopadhyay, S., 2012. Early differentiation and volatile accretion recorded in deep-mantle neon and xenon. Nature 486, 101-104.

Murphy, C.A., Jackson, J.M., Sturhahn, W., Chen, B., 2011. Melting and thermal pressure of hcp-Fe from the phonon density of states. Phys. Earth Planet. Inter. 188, 114-120.

Noguchi, M., Komabayashi, T., Hirose, K., Ohishi, Y., 2013. High-temperature compression experiments of $\mathrm{CaSiO}_{3}$ perovskite to lowermost mantle conditions and its thermal equation of state. Phys. Chem. Min. 40, 81-91.

Nomura, R., Ozawa, H., Tateno, S., Hirose, K., Hernlund, J., Muto, S., Ishii, H., Hiraoka, N., 2011. Spin crossover and iron-rich silicate melt in the Earths deep mantle. Nature 473, 199-203.

Ohta, K., Fujino, K., Kuwayama, Y., Kondo, T., Shimizu, K., Ohishi, Y., 2014. Highly conductive iron-rich $(\mathrm{Mg}, \mathrm{Fe}) \mathrm{O}$ magnesiowüstite and its stability in the Earth's lower mantle. J. Geophys. Res. 119, 4656-4665.

Ozawa, H., Hirose, K., Ohta, K., Ishii, H., Hiraoka, N., Ohishi, Y., Seto, Y., 2011. Spin crossover, structural change, and metallization in NiAs-type FeO at high pressure. Phys. Rev. B 84, 134417.

Ozawa, H., Hirose, K., Tateno, S., Sata, N., Ohishi, Y., 2010. Phase transition boundary between B1 and B8 structures of FeO up to 210 GPa. Phys. Earth Planet. Inter. 179, 1157-163. 
Panero, W.R., Jeanloz, R., 2001. Temperature gradients in the laser-heated diamond anvil cell. J. Geophys. Res. 106, 6493-6498.

Prakapenka, V.B., Kuba, A., Kuznetsov, A., Kaskin, A., Shkurikhin, O., Dera, P., Rivers, M.L., Sutton, S.R., 2008. Advanced flat top laser heating system for high pressure research at GSECARS: application to the melting behavior of germanium. High Press. Res. 28, 225-235.

Richet, P., Mao, H.k., Bell, P.M., 1989. Bulk Moduli of Magnesiowüstites From Static Compression Measurements. J. Geophys. Res. 94, 3037-3045.

Ringwood, A.E., 1975. Bulk Moduli of Magnesiowüstites From Static Compression Measurements. McGraw-Hill, New York.

Rivers, M., Prakapenka, V.B., Kubo, A., Pullins, C., Holl, C.M., Jacobsen, S.D., 2008. The COMPRES/GSECARS gas-loading system for diamond anvil cells at the Advanced Photon Source. High Press. Res. 28, 273-292.

Rost, S., Garnero, E.J., Williams, Q., 2006. Fine-scale ultralow-velocity zone structure from high-frequency seismic array data. J. Geophys. Res. 111, B09310.

Seagle, C., Heinz, D., Campbell, A., Prakapenka, V., Wanless, S., 2008. Melting and thermal expansion in the $\mathrm{Fe}-\mathrm{FeO}$ system at high pressure. Earth Planet. Sci. Lett. 265, 655-665.

Shen, G., Rivers, M.L., Wang, Y., Sutton, S.R., 2001. Laser heated diamond cell system at the Advanced Photon Source for in situ x-ray measurements at high pressure and temperature. Rev. Sci. Instrum. 72, 1273-1282.

Shim, S., Duffy, T.S., Shen, G., 2000. The stability and P-V-T equation of state of $\mathrm{CaSiO}_{3}$ perovskite in the Earth's lower mantle. J. Geophys. Res. 105, $25,955-25,968$.

Shu, J., Mao, H.k., Hu, J., Fei, Y., Hemley, R.J., 1998. Single-Crystal X-ray Diffraction of Wüstite to $30 \mathrm{GPa}$ Hydrostatic Pressure. N. Jb. Miner. Abh. 172, 309-323. 
Speziale, S., Milner, A., Lee, V.E., Clark, S.M., Pasternak, M.P., Jeanloz, R., 2005. Iron spin transition in Earth's mantle. Proc. Natl. Acad. of Sci. 102, 17918-17922.

Sturhahn, W., 2000. CONUSS and PHOENIX: Evaluation of nuclear resonant scattering data. Hyperfine Interactions 125, 149-172.

Sturhahn, W., 2015. www.nrixs.com.

Sturhahn, W., Jackson, J.M., 2007. Geophysical applications of nuclear resonant spectroscopy. GSA Special Papers 421, 157.

Sun, D., Helmberger, D.V., Jackson, J.M., Clayton, R.W., Bower, D.J., 2013. Rolling hills on the core-mantle boundary. Earth Planet. Sci. Lett. 361, 333342.

Tackley, P.J., 2012. Dynamics and evolution of the deep mantle resulting from thermal, chemical, phase and melting effects. Earth-Science Reviews 110, $1-25$.

Tange, Y., Kuwayama, Y., Irifune, T., Funakoshi, K.i., Ohishi, Y., 2012. P-V-T equation of state of $\mathrm{MgSiO}_{3}$ perovskite based on the $\mathrm{MgO}$ pressure scale: A comprehensive reference for mineralogy of the lower mantle. J. Geophys. Res. 117, B06201.

Tange, Y., Nishihara, Y., Tsuchiya, T., 2009. Unified analyses for $P-V-T$ equation of state of $\mathrm{MgO}$ : A solution for pressure-scale problems in high $P-T$ experiments. J. Geophys. Res. 114, B03208.

Westrenen, W.v., Li, J., Fei, Y., Frank, M.R., Hellwig, H., Komabayashi, T., Mibe, K., Minarik, W.G., Orman, J.A.V., Watson, H.C., Funakoshi, K.i., Schmidt, M.W., 2005. Thermoelastic properties of $\left(\mathrm{Mg}_{0.64} \mathrm{Fe}_{0.36}\right) \mathrm{O}$ ferropericlase based on in situ X-ray diffraction to 26.7 GPa and 2173 K. Phys. Earth Planet. Inter. 151, 163-176. 
Wicks, J.K., 2013. Sound Velocities and Equation of State of iron-rich (Mg,Fe)O. Ph.D. thesis. California Institute of Technology.

Wicks, J.K., Jackson, J.M., Sturhahn, W., 2010. Very low sound velocities in iron-rich $(\mathrm{Mg}, \mathrm{Fe}) \mathrm{O}$ : Implications for the core-mantle boundary region. Geophys. Res. Lett. 37, L15304.

Williams, Q., Revenaugh, J., Garnero, E., 1998. A Correlation Between UltraLow Basal Velocities in the Mantle and Hot Spots. Science 281, 546.

Zhang, J., 2000. Effect of pressure on the thermal expansion of $\mathrm{MgO}$ up to 8.2 GPa. Phys. Chem. Min. 27, 145-148.

Zhang, J., Kostak, P., 2002. Thermal equation of state of magnesiowüstite $\left(\mathrm{Mg}_{0.6} \mathrm{Fe}_{0.4}\right)$ O. Phys. Earth Planet. Inter. 129, 301-311.

Zhang, J., Zhao, Y., 2005. Effects of defect and pressure on the thermal expansivity of $\mathrm{Fe}_{X} \mathrm{O}$. Phys. Chem. Min. 32, 241-247.

\section{Appendix A. Parameter fitting}

Here we describe the details of the thermal equation of state parameter fitting. These details are also provided in the complete manual to MINUTI, provided by Sturhahn (2015). The input data for the seos executable in MINUTI are specified as $N$ sets $\left\{p_{i}, V_{i}, T_{i}, \delta p_{i}, \delta V_{i}, \delta T_{i}\right\}$ consisting of pressure, volume, temperature, and their uncertainties. The EOS is fitted to these data by variation of $n$ parameters $\left\{x_{j}\right\}$ by minimizing the normalized mean-square deviation (method of weighted least squares), with the reduced $\chi^{2}$ described by

$$
\begin{array}{r}
\chi^{2}=\frac{1}{(N+p-n)}\left\{\sum_{i=1}^{N} w_{i}\left(V_{i}-V\left(p_{i}, T_{i},\left\{x_{j}\right\}\right)\right)^{2}\right. \\
\left.+\sum_{k=1}^{p} \frac{\left(x_{k}-X_{k}\right)^{2}}{\delta^{2} X_{k}}\right\} .
\end{array}
$$


Some number $p$ of the fit parameters may have priors $X_{k}$ with uncertainties $\delta X_{k}$. The weights $w_{i}$ are determined by uncertainties of the data via

$$
\begin{aligned}
w_{i}^{-1}=\delta^{2} V_{i}+ & \left(\frac{\partial V}{\partial p}\right)_{T}^{2} \delta^{2} p_{i}+\left(\frac{\partial V}{\partial T}\right)_{p}^{2} \delta^{2} T_{i} b= \\
& \delta^{2} V_{i}+V_{i}^{2}\left(\frac{\delta^{2} p_{i}}{K_{i}^{2}}+\alpha_{i}^{2} \delta^{2} T_{i}\right),
\end{aligned}
$$

where $K_{i}$ and $\alpha_{i}$ are bulk modulus and thermal expansion calculated from the EOS at $\left\{p_{i}, T_{i}\right\}$, respectively. If data and priors constrain the fit parameters reasonably well a solution with minimal $\chi^{2}$ is obtained. These optimal parameters have errors related to data variation and prior uncertainties. The errors are estimated as variances (square errors) by

$$
\begin{array}{r}
\delta x_{j}=\sqrt{\sigma_{j j}} \text { with } \sigma_{j j^{\prime}}= \\
\chi_{\text {min }}^{2}\left[\sum_{i=1}^{N} w_{i} \frac{\partial V\left(p_{i}, T_{i}\right)}{\partial x_{l}} \frac{\partial V\left(p_{i}, T_{i}\right)}{\partial x_{l^{\prime}}}+\delta_{l l^{\prime}} \frac{1}{\delta^{2} X_{l}}\right]_{j j^{\prime}}^{-1},
\end{array}
$$

where $\sigma_{j j^{\prime}}$ is the covariance matrix and $[\ldots]^{-1}$ denotes matrix inversion. The derivatives are calculated with the optimal parameters. The fit-parameter correlation matrix is given by

$$
c_{j j^{\prime}}=\frac{\sigma_{j j^{\prime}}}{\sqrt{\sigma_{j j^{\prime} \sigma^{\prime} j^{\prime}}}} .
$$

The variance of a function $F$ of the fit parameters can be calculated as

$$
\delta^{2} F\left(\left\{x_{j}\right\}\right)=\sum_{j j^{\prime}=1}^{n} \sigma_{j j^{\prime}} \frac{\partial F}{\partial x_{j}} \frac{\partial F}{\partial x_{j^{\prime}}}
$$

The fit-parameter correlation matrix for each fitting result is reported in Appendix C.

\section{Appendix B. EOS parameters and their uncertainties}

The isothermal bulk modulus is calculated by direct differentiation of the EOS

$$
K(p, T)=-\left(\frac{\partial p}{\partial \ln V}\right)_{T}
$$


The seismic velocity is calculated via

$$
v_{\phi}(p, T)=\sqrt{(1+\alpha \gamma T)\left(K / \rho_{0}\right)\left(V / V_{0}\right)}
$$

737

where $\alpha$ is the thermal expansion coefficient, $\gamma$ is the is the Debye-Grüneisen parameter, $\rho_{0}$ is the reference density. If fit parameters are defined the variances are calculated using (A.5) with the derivatives

$$
\frac{1}{K} \frac{\partial K}{\partial x_{j}}=\frac{1}{V} \frac{\partial V}{\partial x_{j}}+\frac{K}{V} \frac{\partial}{\partial p}\left(\frac{\partial V}{\partial x_{j}}\right)
$$

and

$$
\frac{1}{v_{\phi}} \frac{\partial v_{\phi}}{\partial x_{j}}=\frac{1}{V} \frac{\partial V}{\partial x_{j}}+\frac{K}{2 V} \frac{\partial}{\partial p}\left(\frac{\partial V}{\partial x_{j}}\right) .
$$

Thermal expansion is calculated according to

$$
\alpha=\frac{1}{V}\left(\frac{\partial V}{\partial T}\right)_{p}=-\frac{1}{V}\left(\frac{\partial S}{\partial p}\right)_{T} .
$$

The thermal contribution to the entropy $S$ is given by

$$
S(V, T)=-3 k_{B} \ln \left(2 \sinh \frac{\Theta}{2 T}\right)+4 k_{B} I\left(\frac{\Theta}{T}\right)+k_{B} \frac{3 \Theta}{2 T},
$$

where $\Theta$ is the Debye temperature and $I$ was defined in Eq. (6). If fit parameters are defined the variance of $\alpha$ is calculated using Eq. A.5 with the derivative

$$
\frac{\partial \alpha}{\partial x_{j}}=-\frac{\alpha}{V} \frac{\partial V}{\partial x_{j}}+\frac{1}{V} \frac{\partial}{\partial p}\left(\frac{\partial S}{\partial x_{j}}\right)
$$




\section{Appendix C. Correlation matrices}

In the fitting procedure of seos, the correlation matrices are provided for all fitted parameters (Equation A.4). The resulting correlation matrices from the fitting of the four different data sets from the two experiments (buffered and unbuffered) are reported here.

Table C.3: B1-Mw94 in the buffered experiment using Fe as a pressure marker (Table 1).

\begin{tabular}{lllll}
\hline \hline & $\gamma_{0}$ & $V_{0}$ & $K_{0 T}$ & $K_{0 T}^{\prime}$ \\
\hline$\gamma_{0}$ & 1.000 & -0.416 & -0.001 & 0.112 \\
$V_{0}$ & -0.416 & 1.000 & -0.897 & 0.799 \\
$K_{0 T}$ & -0.001 & -0.897 & 1.000 & -0.973 \\
$K_{0 T}^{\prime}$ & 0.112 & 0.799 & -0.973 & 1.000 \\
\hline
\end{tabular}

Table C.4: B1-Mw94 in the buffered experiment using $\mathrm{NaCl}$ as a pressure marker (Table 2).

\begin{tabular}{lllll}
\hline \hline & $\gamma_{0}$ & $V_{0}$ & $K_{0 T}$ & $K_{0 T}^{\prime}$ \\
\hline$\gamma_{0}$ & 1.000 & -0.458 & 0.045 & 0.050 \\
$V_{0}$ & -0.458 & 1.000 & -0.896 & 0.807 \\
$K_{0 T}$ & 0.045 & -0.896 & 1.000 & -0.974 \\
$K_{0 T}^{\prime}$ & 0.050 & 0.807 & -0.974 & 1.000 \\
\hline
\end{tabular}

Table C.5: Rhombohedrally-structured Mw94 ( $r-\mathrm{Mw} 94)$ in the buffered experiment at 300 $\mathrm{K}$, using Fe as a pressure marker (Table 1).

\begin{tabular}{llll}
\hline \hline & $V_{0}$ & $K_{0 T}$ & $K_{0 T}^{\prime}$ \\
\hline$V_{0}$ & 1.000 & -0.909 & 0.558 \\
$K_{0 T}$ & -0.909 & 1.000 & -0.843 \\
$K_{0 T}^{\prime}$ & 0.558 & -0.843 & 1.000 \\
\hline
\end{tabular}


Table C.6: $B 1-\mathrm{Mw} 94$ in the unbuffered experiment using $\mathrm{NaCl}$ as a pressure marker (Table $2)$.

\begin{tabular}{lllll}
\hline \hline & $\gamma_{0}$ & $V_{0}$ & $K_{0 T}$ & $K_{0 T}^{\prime}$ \\
\hline$\gamma_{0}$ & 1.000 & -0.337 & -0.162 & 0.244 \\
$V_{0}$ & -0.337 & 1.000 & -0.866 & 0.798 \\
$K_{0 T}$ & -0.162 & -0.866 & 1.000 & -0.987 \\
$K_{0 T}^{\prime}$ & 0.244 & 0.798 & -0.987 & 1.000 \\
\hline
\end{tabular}

Table C.7: $B 1-\mathrm{Mw} 94$ in the unbuffered experiment using $\mathrm{NaCl}$ as a pressure marker, with $K_{0 T}=190 \pm 15 \mathrm{GPa}$ as a prior (Table 2).

\begin{tabular}{lllll}
\hline \hline & $\gamma_{0}$ & $V_{0}$ & $K_{0 T}$ & $K_{0 T}^{\prime}$ \\
\hline$\gamma_{0}$ & 1.000 & -0.602 & -0.083 & 0.299 \\
$V_{0}$ & -0.602 & 1.000 & -0.724 & 0.496 \\
$K_{0 T}$ & -0.083 & -0.724 & 1.000 & -0.945 \\
$K_{0 T}^{\prime}$ & 0.299 & 0.496 & -0.945 & 1.000 \\
\hline
\end{tabular}


Table D.8: Pressure-volume-temperature data for the buffered experiment. $\left(\mathrm{Mg}_{0.06} \mathrm{Fe}_{0.94}\right) \mathrm{O}$ volumes were refined using at least three of the following four reflections: 111, 200, 220, and 311. hcp-Fe volumes were calculated using at least 6 of the following 8 reflections: 100, 200, 101, 102, 110, 103, 200, and 112 . $B 2-\mathrm{NaCl}$ volumes were refined using at least 5 of the 6 following reflections: 100 , $110,111,200,210$, and 211. Ne volumes were calculated from at least one of the two reflections: 111, 200. ${ }^{a}$ Pressure was determined by the equation of state of $h c p$-Fe from Dewaele et al. (2006) and Murphy et al. (2011). ${ }^{b}$ Pressure was determined from the equation of state of $\mathrm{B2}-\mathrm{NaCl}$ (Fei et al., 2007b). ${ }^{c}$ Pressure was determined from the equation of state of Ne (Dewaele et al., 2008). ${ }^{d}$ No error bar is given due to too few reflections. Temperature uncertainties in this table reflect the standard deviation (note that these values were not used in the EOS fitting; see text for details).

\begin{tabular}{cccccccc}
\hline $\begin{array}{c}\mathrm{P}_{F e}^{a} \\
(\mathrm{GPa})\end{array}$ & $\begin{array}{c}\mathrm{P}_{N a C l}^{b} \\
(\mathrm{GPa})\end{array}$ & $\begin{array}{c}\mathrm{P}_{N e}^{c} \\
(\mathrm{GPa})\end{array}$ & $\begin{array}{c}\mathrm{T} \\
(\mathrm{K})\end{array}$ & $\begin{array}{c}\mathrm{V}_{M w 94_{c}} \\
\left(\AA^{3}\right)\end{array}$ & $\begin{array}{c}\mathrm{V}_{F e} \\
\left(\AA^{3}\right)\end{array}$ & $\begin{array}{c}\mathrm{V}_{N a C l} \\
\left(\AA^{3}\right)\end{array}$ & $\begin{array}{c}\mathrm{V}_{N e}^{d} \\
\left(\AA^{3}\right)\end{array}$ \\
\hline $116.5(7)$ & $111.7(5)$ & 116.1 & $1046(37)$ & $6.935(26)$ & $16.50(2)$ & $20.13(2)$ & 25.52 \\
$118.2(7)$ & $113.1(5)$ & 118.6 & $1290(28)$ & $6.943(19)$ & $16.50(2)$ & $20.11(3)$ & 25.48 \\
$118.9(7)$ & $113.5(4)$ & 118.4 & $1406(35)$ & $6.952(20)$ & $16.51(2)$ & $20.12(2)$ & 25.55 \\
$120.1(8)$ & $114.7(5)$ & 119.7 & $1611(52)$ & $6.954(19)$ & $16.53(2)$ & $20.11(3)$ & 25.56 \\
$122.0(7)$ & $115.7(4)$ & 121.7 & $1912(31)$ & $6.950(21)$ & $16.55(2)$ & $20.14(2)$ & 25.59 \\
$102.7(4)$ & $98.9(3)$ & 102.5 & $1143(7)$ & $7.170(14)$ & $16.90(1)$ & $20.86(2)$ & 26.48 \\
$103.1(4)$ & $99.2(3)$ & 102.3 & $1223(6)$ & $7.174(16)$ & $16.90(1)$ & $20.87(2)$ & 26.54 \\
$104.0(4)$ & $99.7(3)$ & 103.6 & $1397(14)$ & $7.191(16)$ & $16.92(1)$ & $20.89(2)$ & 26.54 \\
$105.5(4)$ & $100.9(4)$ & 104.6 & $1640(104)$ & $7.188(14)$ & $16.94(1)$ & $20.89(2)$ & 26.60 \\
$106.3(4)$ & $101.4(3)$ & 105.6 & $1744(40)$ & $7.191(17)$ & $16.94(1)$ & $20.89(2)$ & 26.59 \\
$107.8(4)$ & $102.3(3)$ & 106.5 & $2003(46)$ & $7.197(18)$ & $16.97(1)$ & $20.90(2)$ & 26.67 \\
$95.5(4)$ & $89.6(1.7)$ & 95.5 & $1237(4)$ & $7.257(28)$ & $17.13(1)$ & $21.48(11)$ & 27.07 \\
$96.4(4)$ & $90.8(1.3)$ & 95.9 & $1416(3)$ & $7.286(13)$ & $17.16(1)$ & $21.45(9)$ & 27.15
\end{tabular}




$\begin{array}{lccccccc}97.3(3) & 91.5(1.5) & 96.6 & 1606(19) & 7.296(15) & 17.18(1) & 21.47(10) & 27.20 \\ 98.7(3) & 92.1(1.5) & 97.3 & 1832(21) & 7.343(12) & 17.19(1) & 21.50(10) & 27.29 \\ 90.9(2) & 87.1(3) & 91.7 & 1279(38) & 7.403(25) & 17.29(1) & 21.66(2) & 27.40 \\ 91.3(2) & 87.4(3) & 91.8 & 1396(6) & 7.432(25) & 17.31(1) & 21.68(2) & 27.47 \\ 92.3(2) & 88.3(3) & 92.8 & 1578(36) & 7.428(33) & 17.33(1) & 21.68(2) & 27.50 \\ 94.3(2) & 89.5(3) & 93.6 & 1891(34) & 7.449(18) & 17.36(1) & 21.69(2) & 27.65 \\ 95.1(2) & 90.1(3) & 93.6 & 2036(36) & 7.451(16) & 17.37(1) & 21.70(2) & 27.74 \\ 94.9(2) & 90.3(3) & 94.0 & 2109(81) & 7.429(13) & 17.40(1) & 21.71(2) & 27.76 \\ 85.4(4) & 82.4(5) & 86.4 & 1208(1) & 7.520(27) & 17.45(1) & 21.98(4) & 27.82 \\ 85.5(4) & 82.4(5) & 86.3 & 1287(0) & 7.520(27) & 17.48(2) & 22.00(3) & 27.89 \\ 85.8(3) & 83.0(4) & 86.5 & 1407(37) & 7.524(25) & 17.50(1) & 22.00(3) & 27.95 \\ 86.4(4) & 83.9(3) & 87.1 & 1559(14) & 7.539(29) & 17.52(1) & 21.98(2) & 28.00 \\ 77.7(5) & 75.8(4) & 79.6 & 1106(9) & 7.647(17) & 17.70(2) & 22.44(3) & 28.40 \\ 78.4(5) & 76.3(3) & 80.2 & 1248(4) & 7.661(20) & 17.71(2) & 22.45(3) & 28.44 \\ 80.2(4) & 77.5(4) & 81.6 & 1510(16) & 7.663(16) & 17.73(2) & 22.45(3) & 28.49 \\ 81.0(5) & 78.2(3) & 82.5 & 1694(58) & 7.664(14) & 17.75(2) & 22.47(3) & 28.54 \\ 76.6(3) & 73.2(3) & 77.6 & 1215(5) & 7.704(9) & 17.77(1) & 22.69(2) & 28.68 \\ 77.5(4) & 74.3(3) & 78.2 & 1351(6) & 7.714(8) & 17.78(1) & 22.65(2) & 28.72 \\ 78.4(3) & 74.9(3) & 79.7 & 1516(26) & 7.721(9) & 17.79(1) & 22.67(2) & 28.70 \\ 79.2(3) & 75.5(3) & 80.0 & 1628(24) & 7.724(8) & 17.80(1) & 22.66(3) & 28.75 \\ 80.1(3) & 76.3(3) & 81.4 & 1811(63) & 7.737(7) & 17.83(1) & 22.67(3) & 28.75 \\ 81.9(4) & 77.4(3) & 82.4 & 2048(12) & 7.744(10) & 17.84(1) & 22.66(2) & 28.83 \\ 73.4(3) & 69.8(3) & 73.5 & 1253(1) & 7.799(21) & 17.90(1) & 23.00(3) & 29.14 \\ 74.0(3) & 70.0(4) & 73.7 & 1362(9) & 7.805(22) & 17.91(1) & 23.02(3) & 29.22 \\ 74.9(3) & 70.4(4) & 74.9 & 1506(9) & 7.807(25) & 17.92(1) & 23.05(4) & 29.20 \\ 76.1(3) & 71.3(3) & 75.8 & 1706(16) & 7.809(19) & 17.94(1) & 23.04(3) & 29.27 \\ 77.9(2) & 72.3(3) & 76.5 & 1960(43) & 7.813(16) & 17.97(1) & 23.06(2) & 29.40 \\ 77.4(2) & 72.5(3) & 76.5 & 1922(40) & 7.814(13) & 17.97(1) & 23.03(3) & 29.38 \\ 61.0(5) & 59.1(7) & 63.2 & 1242(4) & 8.047(20) & 18.41(2) & 24.02(7) & 30.40 \\ 61.5(4) & 59.5(5) & 63.9 & 1340(25) & 8.049(18) & 18.42(2) & 24.03(6) & 30.40 \\ & & & & & & & \end{array}$




\begin{tabular}{lccccccc}
$62.5(4)$ & $60.4(4)$ & 65.0 & $1527(6)$ & $8.057(18)$ & $18.45(2)$ & $24.01(4)$ & 30.44 \\
$64.0(3)$ & $61.2(4)$ & 66.2 & $1761(12)$ & $8.061(15)$ & $18.47(1)$ & $24.04(4)$ & 30.51 \\
$65.2(2)$ & $62.0(3)$ & 67.7 & $1959(31)$ & $8.065(17)$ & $18.50(1)$ & $24.06(4)$ & 30.50 \\
$54.5(6)$ & $52.6(4)$ & 56.3 & $1223(4)$ & $8.214(11)$ & $18.70(3)$ & $24.74(5)$ & 31.38 \\
$55.3(6)$ & $53.1(5)$ & 57.0 & $1327(0)$ & $8.216(9)$ & $18.71(3)$ & $24.74(6)$ & 31.40 \\
$57.0(5)$ & $54.3(6)$ & 58.2 & $1570(2)$ & $8.220(8)$ & $18.72(3)$ & $24.72(7)$ & 31.48 \\
$57.7(5)$ & $54.5(5)$ & 59.3 & $1704(16)$ & $8.227(6)$ & $18.74(2)$ & $24.76(6)$ & 31.46 \\
$58.6(4)$ & $55.2(5)$ & 60.0 & $1830(4)$ & $8.229(5)$ & $18.75(2)$ & $24.75(6)$ & 31.49 \\
$59.3(4)$ & $55.4(6)$ & 60.3 & $1918(7)$ & $8.233(15)$ & $18.76(2)$ & $24.77(7)$ & 31.55 \\
$52.3(4)$ & $49.5(3)$ & 52.4 & $1523(8)$ & $8.326(11)$ & $18.94(2)$ & $25.29(4)$ & 32.40 \\
$51.2(4)$ & $48.7(3)$ & 51.5 & $1319(1)$ & $8.316(11)$ & $18.91(2)$ & $25.27(4)$ & 32.30 \\
$53.9(3)$ & $50.2(2)$ & 53.6 & $1740(52)$ & $8.337(10)$ & $18.95(2)$ & $25.31(3)$ & 32.47 \\
$44.3(6)$ & $41.5(5)$ & 45.3 & $1336(25)$ & $8.562(26)$ & $19.28(4)$ & $26.30(8)$ & 33.53 \\
$43.7(8)$ & $41.6(5)$ & 45.2 & $1354(4)$ & $8.565(22)$ & $19.32(5)$ & $26.30(7)$ & 33.59 \\
$44.4(8)$ & $41.9(4)$ & 45.4 & $1451(28)$ & $8.561(17)$ & $19.33(4)$ & $26.32(6)$ & 33.69 \\
$46.4(5)$ & $42.8(4)$ & 46.6 & $1672(42)$ & $8.558(12)$ & $19.32(3)$ & $26.32(7)$ & 33.77 \\
$47.4(5)$ & $43.4(4)$ & 47.3 & $1822(49)$ & $8.560(13)$ & $19.34(3)$ & $26.33(6)$ & 33.85 \\
$48.1(5)$ & $43.6(3)$ & 47.8 & $1902(110)$ & $8.566(14)$ & $19.34(3)$ & $26.34(5)$ & 33.85 \\
$38.7(4)$ & $37.0(4)$ & 38.8 & $1366(16)$ & $8.693(7)$ & $19.63(2)$ & $27.07(7)$ & 35.12 \\
$39.2(4)$ & $36.9(2)$ & 38.9 & $1431(18)$ & $8.694(7)$ & $19.63(3)$ & $27.12(4)$ & 35.22 \\
$39.8(4)$ & $37.4(3)$ & 39.3 & $1521(33)$ & $8.703(7)$ & $19.64(3)$ & $27.11(6)$ & 35.28 \\
$42.0(4)$ & $38.3(3)$ & 40.9 & $1794(8)$ & $8.719(7)$ & $19.65(3)$ & $27.15(6)$ & 35.36 \\
$42.7(3)$ & $38.8(4)$ & 42.0 & $1906(90)$ & $8.722(20)$ & $19.66(2)$ & $27.13(7)$ & 35.27 \\
\hline & & & & & & &
\end{tabular}


Table D.9: Pressure-volume-temperature data for the unbuffered experiment. $\left(\mathrm{Mg}_{0.06} \mathrm{Fe}_{0.94}\right) \mathrm{O}$ volumes were refined using the three reflections: 111, 200, and 220. $B 2-\mathrm{NaCl}$ volumes were refined using at least 3 of the 4 following reflections: $100,110,111$, and 200 . Ne volumes were calculated from at least one of the two reflections: 111, 200. ${ }^{a}$ Pressure was determined from the equation of state of $B 2-\mathrm{NaCl}$ (Fei et al., 2007b). ${ }^{b}$ Pressure was determined from the equation of state of $\mathrm{Ne}$ (Dewaele et al., 2008). ${ }^{c}$ No error bar is given due to too few reflections. Temperature uncertainties in this table reflect the standard deviation (note that these values were not used in the EOS fitting; see text for details).

\begin{tabular}{lccccc}
\hline $\mathrm{P}_{N a C l}^{a}$ & $\mathrm{P}_{N e}^{b}$ & $\mathrm{~T}$ & $\mathrm{~V}_{M w 94}$ & $\mathrm{~V}_{N a C l}$ & $\mathrm{~V}_{N e}^{c}$ \\
$(\mathrm{GPa})$ & $(\mathrm{GPa})$ & $(\mathrm{K})$ & $\left(\AA^{3}\right)$ & $\left(\AA^{3}\right)$ & $\left(\AA^{3}\right)$ \\
\hline $71.5(4)$ & 73.1 & $1227(11)$ & $7.77(2)$ & $22.84(3)$ & 29.17 \\
$71.7(6)$ & 73.2 & $1312(14)$ & $7.78(2)$ & $22.85(5)$ & 29.23 \\
$72.0(5)$ & 73.5 & $1442(28)$ & $7.79(2)$ & $22.88(4)$ & 29.30 \\
$71.4(4)$ & 70.2 & $1208(23)$ & $7.77(2)$ & $22.85(3)$ & 28.77 \\
$71.7(4)$ & 72.8 & $1317(27)$ & $7.78(2)$ & $22.86(4)$ & 29.19 \\
$71.9(4)$ & 72.9 & $1413(26)$ & $7.78(2)$ & $22.88(4)$ & 29.26 \\
$69.5(5)$ & 71.0 & $1192(44)$ & $7.86(3)$ & $23.00(5)$ & 29.38 \\
$70.0(3)$ & 70.6 & $1306(62)$ & $7.85(2)$ & $23.01(3)$ & 29.52 \\
$70.5(3)$ & 70.9 & $1433(19)$ & $7.86(1)$ & $23.01(3)$ & 29.61 \\
$69.9(3)$ & 68.1 & $1173(15)$ & $7.83(2)$ & $22.96(3)$ & 29.00 \\
$70.1(3)$ & 70.3 & $1279(36)$ & $7.84(2)$ & $22.98(2)$ & 29.45 \\
$70.5(4)$ & 70.5 & $1396(49)$ & $7.85(2)$ & $23.00(3)$ & 29.52 \\
$67.4(7)$ & 69.3 & $1226(28)$ & $7.89(6)$ & $23.21(7)$ & 29.61 \\
$67.7(6)$ & 69.1 & $1293(17)$ & $7.89(5)$ & $23.21(6)$ & 29.69 \\
$68.0(5)$ & 69.0 & $1403(20)$ & $7.90(5)$ & $23.22(5)$ & 29.80 \\
$67.4(5)$ & 68.9 & $1180(23)$ & $7.88(5)$ & $23.18(5)$ & 29.61 \\
$67.8(5)$ & 69.3 & $1306(7)$ & $7.89(5)$ & $23.20(5)$ & 29.68 \\
$67.9(6)$ & 69.3 & $1351(15)$ & $7.89(5)$ & $23.21(5)$ & 29.72
\end{tabular}




$\begin{array}{llllll}68.1(5) & 69.3 & 1420(16) & 7.90(4) & 23.22(5) & 29.78 \\ 63.3(2) & 65.8 & 1216(7) & 7.96(4) & 23.58(2) & 30.04 \\ 63.6(2) & 63.8 & 1295(2) & 7.97(4) & 23.59(2) & 30.38 \\ 64.1(3) & 64.9 & 1412(17) & 7.97(3) & 23.60(3) & 30.34 \\ 63.6(1) & 65.7 & 1212(10) & 7.95(3) & 23.55(1) & 30.04 \\ 63.8(2) & 66.2 & 1289(11) & 7.96(3) & 23.57(2) & 30.05 \\ 64.1(3) & 65.6 & 1430(13) & 7.97(3) & 23.60(3) & 30.27 \\ 60.5(4) & 61.0 & 1215(27) & 8.05(5) & 23.86(4) & 30.68 \\ 61.1(1) & 62.1 & 1335(14) & 8.05(4) & 23.86(1) & 30.64 \\ 61.4(3) & 59.7 & 1424(15) & 8.05(3) & 23.87(3) & 31.08 \\ 62.1(7) & 62.6 & 1446(23) & 8.03(1) & 23.81(7) & 30.69 \\ 57.6(2) & 59.0 & 1203(24) & 8.13(4) & 24.16(3) & 30.95 \\ 58.0(3) & 57.9 & 1317(40) & 8.13(3) & 24.18(3) & 31.24 \\ 58.4(2) & 57.5 & 1424(43) & 8.13(3) & 24.19(2) & 31.42 \\ 58.3(3) & 58.3 & 1390(20) & 8.13(3) & 24.18(3) & 31.26 \\ 57.9(2) & 59.4 & 1207(36) & 8.11(3) & 24.13(2) & 30.90 \\ 58.1(2) & 57.7 & 1308(12) & 8.12(3) & 24.16(2) & 31.26 \\ 58.4(1) & 57.8 & 1382(19) & 8.12(3) & 24.16(1) & 31.33 \\ 58.8(4) & 59.4 & 1451(37) & 8.13(3) & 24.16(5) & 31.17 \\ 55.7(2) & 56.5 & 1245(22) & 8.18(3) & 24.39(2) & 31.38 \\ 56.2(4) & 54.4 & 1337(18) & 8.18(2) & 24.39(4) & 31.83 \\ 56.1(2) & 55.1 & 1371(16) & 8.18(2) & 24.41(3) & 31.75 \\ 56.1(3) & 56.1 & 1386(32) & 8.17(2) & 24.41(3) & 31.60 \\ 55.9(5) & 55.5 & 1270(23) & 8.15(3) & 24.38(6) & 31.57 \\ 56.1(2) & 55.6 & 1346(18) & 8.16(3) & 24.40(2) & 31.64 \\ 56.4(3) & 55.6 & 1422(15) & 8.17(2) & 24.40(3) & 31.73 \\ 54.0(1.3) & 55.6 & 1224(38) & 8.21(4) & 24.58(16) & 31.50 \\ 54.6(1.1) & 55.5 & 1396(42) & 8.22(3) & 24.59(13) & 31.70 \\ 55.4(1.2) & 55.3 & 1579(16) & 8.23(2) & 24.59(14) & 31.96 \\ 55.7(1.0) & 55.9 & 1670(24) & 8.23(1) & 24.60(12) & 31.98\end{array}$




$\begin{array}{lccccc}55.8(1.0) & 55.5 & 1731(9) & 8.24(1) & 24.63(11) & 32.12 \\ 54.4(7) & 54.9 & 1140(21) & 8.15(8) & 24.49(8) & 31.51 \\ 54.7(6) & 54.7 & 1239(6) & 8.16(6) & 24.51(7) & 31.65 \\ 55.4(6) & 54.8 & 1437(16) & 8.18(3) & 24.52(6) & 31.88 \\ 55.3(6) & 54.1 & 1483(53) & 8.22(1) & 24.56(6) & 32.05 \\ 46.8(1.1) & 48.6 & 1195(20) & 8.39(4) & 25.45(15) & 32.67 \\ 47.6(1.0) & 49.4 & 1398(34) & 8.40(3) & 25.46(13) & 32.79 \\ 48.2(8) & 48.7 & 1591(24) & 8.41(2) & 25.50(11) & 33.19 \\ 48.8(8) & 50.0 & 1760(26) & 8.42(1) & 25.51(10) & 33.19 \\ 45.2(1.1) & 48.8 & 1248(24) & 8.42(5) & 25.71(15) & 32.71 \\ 45.9(1.1) & 49.1 & 1429(15) & 8.42(4) & 25.72(16) & 32.90 \\ 46.5(1.1) & 48.8 & 1613(15) & 8.44(3) & 25.75(15) & 33.21 \\ 46.8(1.0) & 51.3 & 1705(35) & 8.45(2) & 25.75(14) & 32.84 \\ 41.3(1.0) & 44.3 & 1186(32) & 8.55(2) & 26.23(15) & 33.52 \\ 42.0(8) & 45.9 & 1387(6) & 8.56(2) & 26.26(13) & 33.48 \\ 42.7(8) & 46.2 & 1561(33) & 8.57(2) & 26.27(13) & 33.69 \\ 42.8(8) & 45.7 & 1584(12) & 8.57(2) & 26.27(12) & 33.83 \\ 38.6(1.0) & 39.1 & 1265(35) & 8.62(4) & 26.72(16) & 3.27 \\ 39.1(9) & 39.3 & 1398(37) & 8.63(4) & 26.72(15) & 3.27 \\ 39.1(9) & 39.4 & 1395(23) & 8.63(4) & 26.72(15) & 3.27 \\ 39.7(8) & & 1562(38) & 8.65(4) & 26.75(14) & \\ 39.8(8) & & 1613(28) & 8.65(4) & 26.76(14) & \\ 38.4(7) & 39.0 & 1165(51) & 8.60(3) & 26.69(12) & 3.26 \\ 39.2(9) & & 1436(45) & 8.63(3) & 26.74(15) & \\ 39.7(8) & & 1594(17) & 8.65(4) & 26.76(14) & \\ 34.6(6) & 35.5 & 1207(77) & 8.72(1) & 27.37(11) & 35.75 \\ 35.0(7) & 35.9 & 1295(68) & 8.73(1) & 27.36(12) & 35.78 \\ 35.3(6) & 36.4 & 1384(50) & 8.76(1) & 27.38(12) & 35.82 \\ 35.5(6) & 37.2 & 1475(25) & 8.77(1) & 27.40(11) & 35.77 \\ 33.2(9) & 34.1 & 1224(31) & 8.76(2) & 27.64(17) & 36.20\end{array}$




\begin{tabular}{llllll}
$33.6(7)$ & 35.3 & $1454(41)$ & $8.79(1)$ & $27.74(13)$ & 36.32 \\
$34.3(1.1)$ & 36.4 & $1630(31)$ & $8.81(1)$ & $27.76(22)$ & 36.35 \\
$31.9(7)$ & 34.1 & $1235(36)$ & $8.75(7)$ & $27.90(15)$ & 36.22 \\
$32.2(9)$ & 33.9 & $1384(65)$ & $8.78(5)$ & $27.97(19)$ & 36.59 \\
$32.4(8)$ & 34.4 & $1526(21)$ & $8.82(4)$ & $28.04(17)$ & 36.75 \\
$32.4(5)$ & 33.9 & $1391(60)$ & $8.79(4)$ & $27.93(9)$ & 36.62 \\
$32.8(4)$ & 34.3 & $1510(31)$ & $8.81(4)$ & $27.95(8)$ & 36.74 \\
\hline
\end{tabular}




\section{Appendix E. Unexplained Peaks}

As described in the text, weak unexplained peaks were observed in our unbuffered dataset (Figure 1). It has been proposed that vacancy concentrations in non-stoichiometric FeO-bearing samples are reduced with the exsolution of $(\mathrm{Fe}, \mathrm{Mg}) \mathrm{Fe}_{2} \mathrm{O}_{4}$ at high pressure and temperature, according to

$$
\left(M g_{x} F e_{y}\right) O \rightarrow a\left(M g_{x^{\prime}} F e_{1-x^{\prime}}\right) F e_{2} O_{4}+b\left(M g_{x^{\prime \prime}} F e_{y^{\prime \prime}}\right) O
$$

where $\left(x^{\prime \prime}+y^{\prime \prime}\right)>(x+y)$, ensuring the stoichiometry of the $(\mathrm{Mg}, \mathrm{Fe}) \mathrm{O}$ phase regardless of oxygen fugacity (Zhang and Zhao, 2005; McCammon et al., 1998; Fei, 1996).

In Figure E.10, measured XRD patterns are compared to candidate oxides measured in other studies. As the chemical composition of the Mw94 at the P-T conditions sampled in this study is not known, it could be possible that the unidentified peaks belong to a phase with composition $(\mathrm{Mg}, \mathrm{Fe})_{3} \mathrm{O}_{4}$, but they do not match that of $\mathrm{MgFe}_{2} \mathrm{O}_{4}$ or $h-\mathrm{Fe}_{3} \mathrm{O}_{4}$. They are consistent, however, with peaks of $\mathrm{Fe}_{4} \mathrm{O}_{5}$. We do not see any of the remaining several peaks predicted for this phase, the most intense of which fall under ours (8 degrees), which may rule it out as a potential candidate. More dedicated studies need to be carried out to precisely determine both the composition, identity, and phase relations of exsolution products before definite claims can be made. 


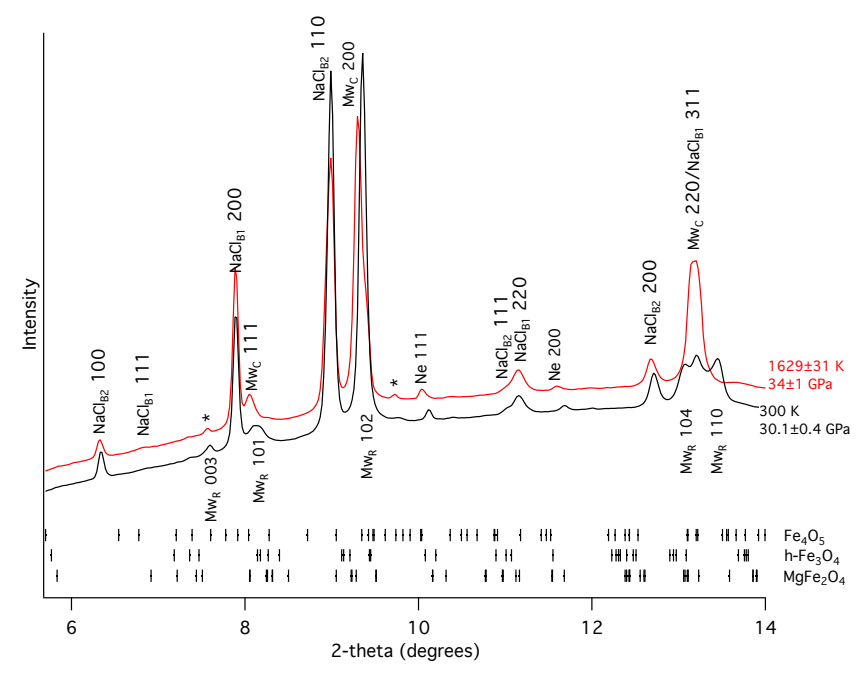

Figure E.10: Example integrated XRD patterns for the unbuffered dataset showing peak identifications for $\left(\mathrm{Mg}_{0.06} \mathrm{Fe}_{0.94}\right) \mathrm{O}, \mathrm{B2}-\mathrm{NaCl}$, and $\mathrm{Ne}$. Pressures were determined using the equation of state of $B 2-\mathrm{NaCl}$ (Fei et al., 2007b). ( $\left.\mathrm{Mg}_{0.06} \mathrm{Fe}_{0.94}\right) \mathrm{O}$ is cubic at high temperature $\left(\mathrm{Mw}_{C}, F m-3 m\right)$ and rhombohedral at room temperature upon quench $\left(\mathrm{Mw}_{R}, R-3 m\right)$. In this quench pattern at $300 \mathrm{~K}$, a mixture of cubic and rhombohedral Mw94 is observed. Unidentified peaks are labeled with *. For comparison, reflections of candidate iron oxides are shown below: $\mathrm{MgFe}_{2} \mathrm{O}_{4}$ measured at $31.6 \mathrm{GPa}$ (Andrault and Bolfan-Casanova, 2001), $h$ - $\mathrm{Fe}_{3} \mathrm{O}_{4}$ calculated at $31 \mathrm{GPa}$ (Dubrovinsky et al., 2003), and $\mathrm{Fe}_{4} \mathrm{O}_{5}$ measured at $30 \mathrm{GPa}$ (Lavina et al., 2011) 